University of Massachusetts Amherst

ScholarWorks@UMass Amherst

Masters Theses 1911 - February 2014

January 2008

\title{
A Novel Process for Continuous Thermal Embossing of Large- Area Nanopatterns onto Polymer Films
}

Matthew D. Fagan

University of Massachusetts Amherst

Follow this and additional works at: https://scholarworks.umass.edu/theses

Fagan, Matthew D., "A Novel Process for Continuous Thermal Embossing of Large-Area Nanopatterns onto Polymer Films" (2008). Masters Theses 1911 - February 2014. 200.

Retrieved from https://scholarworks.umass.edu/theses/200

This thesis is brought to you for free and open access by ScholarWorks@UMass Amherst. It has been accepted for inclusion in Masters Theses 1911 - February 2014 by an authorized administrator of ScholarWorks@UMass Amherst. For more information, please contact scholarworks@library.umass.edu. 


\section{A NOVEL PROCESS FOR CONTINUOUS THERMAL EMBOSSING OF LARGE-AREA NANOPATTERNS ONTO POLYMER FILMS}

A Thesis Presented

By

MATTHEW D. FAGAN

Submitted to the Graduate School of the University of Massachusetts Amherst in partial fulfillment of the requirements for the degree of MASTER OF SCIENCE IN MECHANICAL ENGINEERING

September 2008

Department of Mechanical and Industrial Engineering 


\section{A NOVEL PROCESS FOR CONTINUOUS THERMAL EMBOSSING OF}

\section{LARGE-AREA NANOPATTERNS ONTO POLYMER FILMS}

A Thesis Presented

By

MATTHEW D. FAGAN

Approved as to style and content by:

Byung H. Kim, Chair

Jonathan P. Rothstein, Member

Kenneth R. Carter, Member

Mario Rotea, Department Head

Department of Mechanical and Industrial

Engineering 
To My Family 


\section{ACKNOWLEDGMENTS}

I would like to thank my advisor, Professor Byung Kim, for his patience, guidance, and instruction throughout the course of this project and my time as a graduate student. I would like to further extend my appreciation to Professor Rothstein and Professor Carter for their willingness to serve on my committee.

I will also thank Al Rakouskas for his assistance with software and electromechanical-device related troubleshooting; and Rick Winn, Miles Eastman, and Rick Miastkowski for their help in the machine shop.

I would also like to thank my lab members MingWen Hu and Sharad Raj for their support and assistance, and also Wei Zhang for his assistance in characterization of the patterns using the SEM.

I acknowledge all financial support for this project from the National Science Foundation and the Gillette Company. 


\author{
ABSTRACT \\ A NOVEL PROCESS FOR CONTINUOUS THERMAL EMBOSSING OF LARGE- \\ AREA NANOPATTERNS ONTO POLYMER FILMS \\ SEPTEMBER 2008 \\ MATTHEW D. FAGAN, B.S., UNIVERSITY OF MASSACHUSETTS AMHERST \\ M.S., UNIVERSITY OF MASSACHUSETTS AMHERST \\ Directed by: Professor Byung H. Kim
}

As imprint lithography becomes commonplace in industrial manufacturing, the need for fast, reliable modifications to the process are of great importance. In particular, the Roll-to-Roll Nanoimprint Lithography (R2RNIL) method has been proven to yield large areas of continuous, robust patterns in the micro- and nanometer range. A thermal embossing R2RNIL system has been developed that is capable of providing a mold heating rate of $100^{\circ} \mathrm{C} / \mathrm{s}$ with sufficient temperature control to produce large-area patterns continuously at a rate in excess of four feet per minute. This process uses a novel loopedconveyor mold, allowing longer continuous patterns to be produced with superior temperature control than other methods of R2RNIL. Various patterns in the micro- and nanometer domains were replicated using this process. 


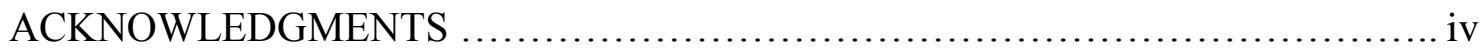

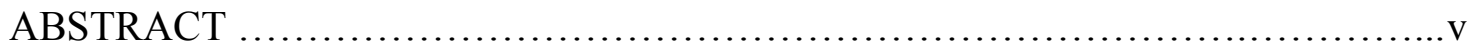

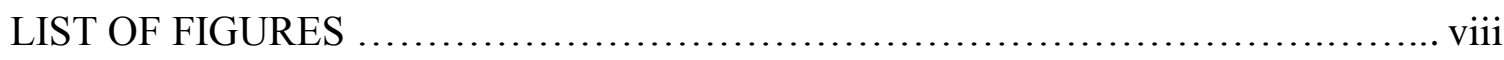

LIST OF SYMBOLS AND ABBRIVATIONS $\ldots \ldots \ldots \ldots \ldots \ldots \ldots \ldots \ldots \ldots \ldots \ldots \ldots$

\section{CHAPTER}

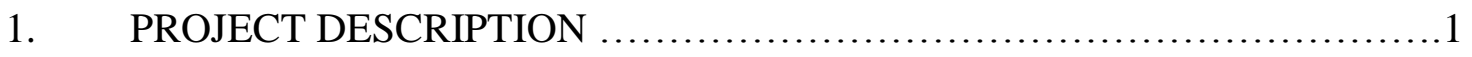

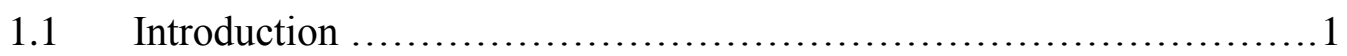

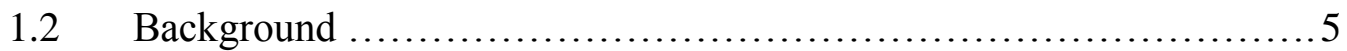

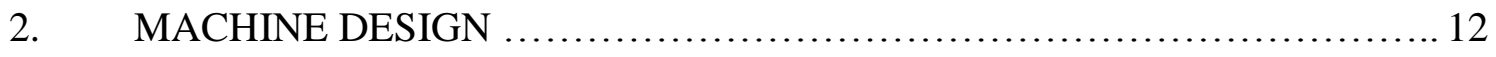

2.1. Base Machine ….............................................. 12

2.2. Induction Heating ............................................... 13

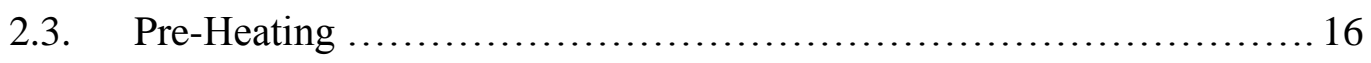

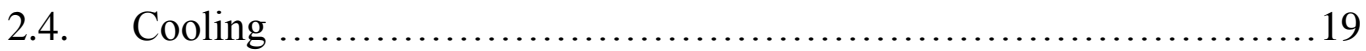

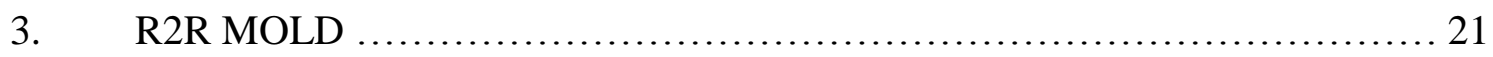

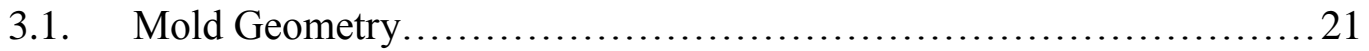

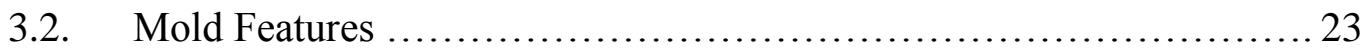

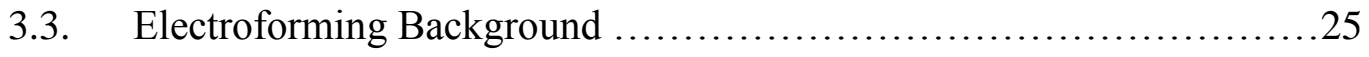

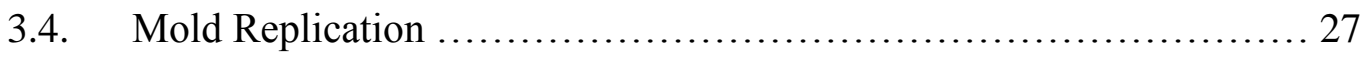

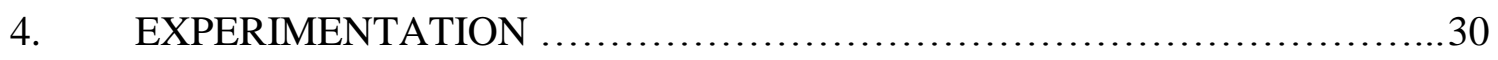

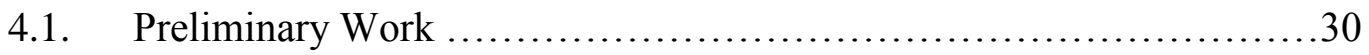




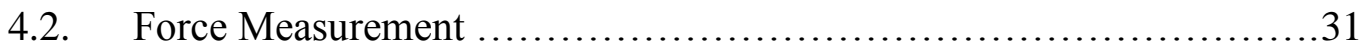

4.3. Mold Surface Temperature Measurement ........................... 33

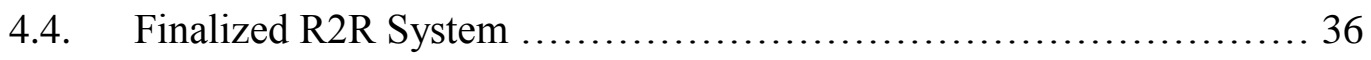

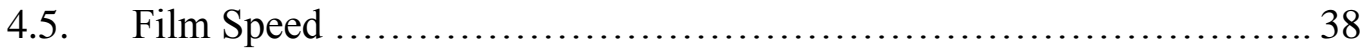

4.6. R2R Experimental Procedure ............................... 42

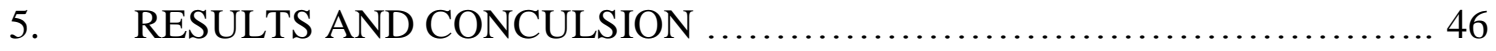

5.1. Pattern Characterization ........................................ 46

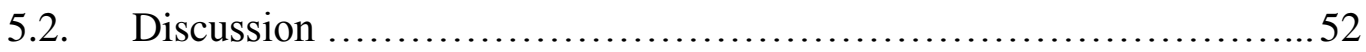

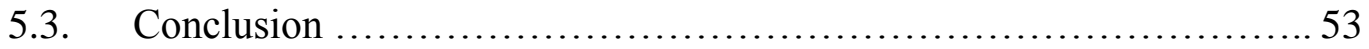

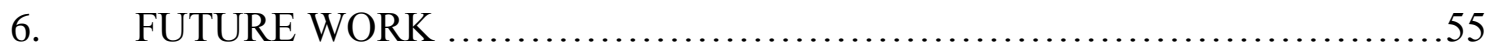

APPENDIX: INDUCTION HEATER TUNING AND CODE $\ldots \ldots \ldots \ldots \ldots \ldots \ldots \ldots . . . \ldots 7$

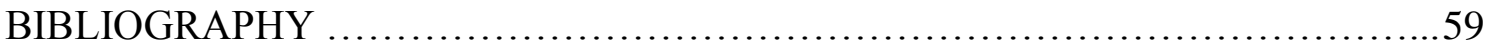




\section{LIST OF FIGURES}

Figure $\quad$ Page

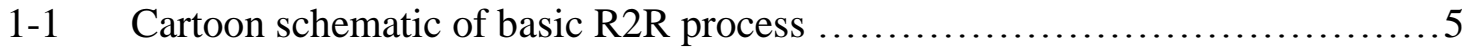

1-2 Temperature-modulus relationship for Polystyrene $\left(\mathrm{Tg}=100^{\circ} \mathrm{C}\right) \ldots \ldots \ldots \ldots \ldots . . \ldots$

1-3 Embossing stage of R2R showing temperatures in their respective areas .......8

1-4 Tensile properties of a similar PET material used in this project ...............8

2-1 Working section of unmodified Stanat roller press used as base machine for

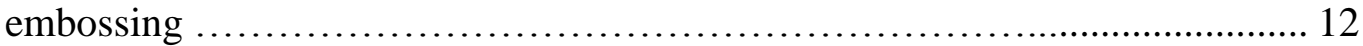

2-2 Absorption spectrum of PET film used for embossing experiments............. 16

2-3 Emission spectrum of UV light used as pre-heating source................. 17

2-4 Temperature response of PET film and thermocouple under UV light.......... 18

2-5 Backside of the embossing machine .................................. 19

2-6 Embossing roll assembly; exploded view (a), transverse center x-section (b), and parallel x-section showing flow of cooling air (c) $\ldots \ldots \ldots \ldots \ldots \ldots \ldots \ldots . \ldots \ldots$

3-1 Transition from circular R2R mold to conveyor R2R mold $\ldots \ldots \ldots \ldots \ldots \ldots \ldots . .21$

3-2 Cartoon cross-sectional view of proposed embossing process ................22

3-3 Adhesive connection between mold ribbons ............................. 22

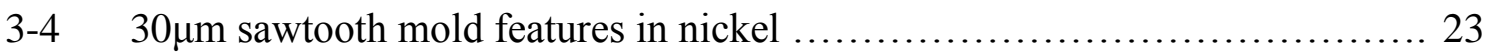

3-5 Overview of the process required for electroforming of a non-conductive mandrel (mold). .................................... 26

3-6 Polycarbonate mandrel with attached molds prior to electroforming ...........28

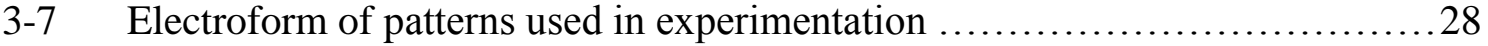


3-8 AFM images of the electroformed PMMA substrate mold (a) located on the top of the electroform (red tint in Figure 3-7) and of the replicated ETFE substrate mold (b) located on the bottom of the electroform (blue-green tint in Figure 3-7)

4-1 Aluminum disks with attached strain gauges used in measuring contact force during embossing (a), and bridges used to convert strain gauge signal (b) ......32

4-2 Mold surface temperature versus time after induction heating for the $30 \mu \mathrm{m}$ nickel mold. First two digits of legend indicate speed of mold (\% maximum roller speed in $1^{\text {st }}$ gear) and last two digits indicate induction heating power (\% maximum)

4-3 Induction heating-temperature response for electroformed Nickel-Cobalt alloy. The legend used here is the same format as that of Figure 4-2

4-4 Panoramic view (a) of completed experimental setup with a magnification

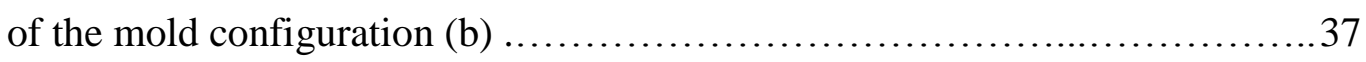

4-5 Model used to represent flow into a micro-/nanofeature ...................... 38

4-6 Semi-log plot of temperature-viscosity relationship of PET according to the WLF equation using generalized polymer constants

4-7 Geometrical representation of embossing stage ........................... 41

4-8 Mold conveyor using a section of electroformed mold ...................... 45

5-1 Diffraction pattern of replicated $30 \mu \mathrm{m}$ sawtooth pattern ......................46

5-2(a) SEM and profilometry results for replicated $30 \mu \mathrm{m}$ patterns at $130^{\circ} \mathrm{C} \ldots \ldots \ldots \ldots . .48$

5-2(b) SEM and profilometry results for replicated $30 \mu \mathrm{m}$ patterns at $250^{\circ} \mathrm{C} \ldots \ldots \ldots \ldots 48$

5-2(c) SEM and profilometry results of the original mold ........................ 49 
5-3(a) Top-down AFM view of the original mold in PMMA with 250nm linewidth, 375nm period, and 200nm height ............................ 50

5-3(b) Tilted AFM section view of the original mold in PMMA with 250nm

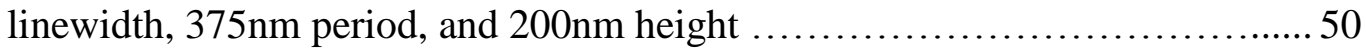

5-3(c) Top down AFM view of the electroformed copy of the PMMA mold ...........51

5-3(d) Top down AFM view after performing R2RNIL on PET using the electroform of the mold, revealing the presence of the structure

5-3(e) Tilted AFM section view of the AFM results after performing R2RNIL on

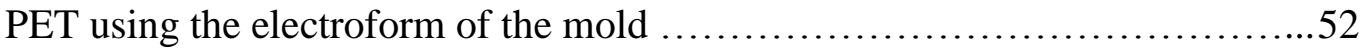

5-4 Illustration of improper mold filling due to shallow mold angle (a), and better mold filling with sharp mold angle (b) 


\section{LIST OF SYMBOLS AND ABBREVIATIONS}

Symbol

D Electric flux density

E Electric field intensity

B Magnetic flux density

H Magnetic field intensity

J Current density

$\mathrm{J}_{\mathrm{S}} \quad$ Current density on surface

Q Joule heat

T Temperature

$\mathrm{T}_{\mathrm{g}} \quad$ Glass transition temperature

t Time

$\rho \quad$ Electrical resistivity

$\delta \quad$ Skin depth

d Depth into heated part

$f \quad$ Induction heating frequency

$\mu_{\mathrm{r}} \quad$ Relative magnetic permeability

$\mu_{0} \quad$ Magnetic constant

P Pressure

$\eta \quad$ Viscosity

$\mathrm{u}_{\mathrm{x}} \quad$ Velocity in $\mathrm{x}$-direction

h Width of nanofeature 
$\Delta \mathrm{x} \quad$ Length of nanofeature

$\mathrm{t}_{\text {fill }} \quad$ Fill time

$\eta_{0} \quad$ Viscosity at glass transition

$\mathrm{C}_{1} \quad$ WLF constant \#1

$\mathrm{C}_{2} \quad$ WLF constant \#2

$\mathrm{L}_{\text {contact }}$ Contact length of embossing stage

$\mathrm{W}_{\text {mold }}$ Width of mold

$t_{\text {contact }}$ Contact time of embossing stage

\begin{tabular}{|c|c|}
\hline \multicolumn{2}{|c|}{ Abbreviations } \\
\hline $\mathrm{R} 2 \mathrm{R}$ & Roll-to-Roll \\
\hline RTR & Rapid Thermal Response \\
\hline NIL & Nanoimprint Lithography \\
\hline $\mathrm{CR}$ & Compression Ratio \\
\hline UV & Ultraviolet \\
\hline PET & Polyethylene Terephthalate \\
\hline ETFE & Ethylene Tetrafluoroethylene \\
\hline PMMA & Poly(Methyl Methacrylate) \\
\hline CTE & Coefficient of Thermal Expansion \\
\hline AFM & Atomic Force Microscopy \\
\hline SEM & Scanning Electron Microscopy \\
\hline
\end{tabular}




\section{CHAPTER 1}

\section{PROJECT DESCRIPTION}

\subsection{Introduction}

In recent years, the demand for micrometer and nanometer sized patterns on macroscopic sized areas on polymer surfaces have increased dramatically. This has been especially true in the electronics and coatings industries whose applications include reflective polarizers, anti-reflective surfaces, drag-reducing surfaces, biologically active surfaces, and many others. In many of these applications it is required of the patterned surface to not only be free of defects on the order of the micropatterns, but also on the order of the macro scale area. A reliable, fast, and low-cost process which has the potential to produce robust, homogeneous patterns on areas $0.1 \mathrm{~m}^{2}$ and larger is critical to success in these industries. [1-12]

Many existing methods currently employed in the production of micropatterns are unsuitable for incorporation into a large area process. Research in areas such as thermal and UV light curing imprint lithography have yielded robust, defect free structures with a resolution as low as $10 \mathrm{~nm}$; however, these methods are limited to areas of tens $\mathrm{cm}^{2}$ or less. This limitation on area is largely due to the high pressures needed for these processes, often in excess of $1 \mathrm{MPa}$; and, more importantly, the size and cost of the molds used to replicate the structures. [3, 7, 9, 13-20]

Roll-to-roll nanoimprint lithography (R2RNIL) has become a promising method in the production of large-area micro-/nanopatterns. $[9,18,21-26]$ This process runs a polymer film through a set of rollers, usually one patterned roll and one or more pressure 
rolls. Three distinct advantages in using this process are the following: contact between rollers effectively concentrates the applied force onto a one dimensional line, creating very high pressures with a low applied force; allowing the use of a small mold to create a significantly larger patterned area; and transitioning from a discontinuous to a continuous process.

Two common methods for creating patterns using R2RNIL include thermal embossing and UV curing. The thermal R2R embossing technique uses a heat source to raise the temperature of the mold above the glass transition temperature of the substrate to be patterned and forces the polymer to flow into the mold features. The mold is then cooled and the patterned substrate lifted off the roll. Tan et al has demonstrated a similar method to demonstrate non-continuous patterns with sub-100nm resolution. [26] UV R2RNIL uses chemical resin consisting of monomer, a crosslinking agent, and a UV sensitive initiator which when exposed to a light source of 400nm wavelength or below initiates a free radical polymerization with the monomer and crosslinker creating a solid polymer network. The UV resin is spread over the surface of a flexible polymer substrate, pressed onto the mold roller, and exposed to high intensity UV light. This method has been demonstrated to produce continuous sub-100nm features. Guo et al has demonstrated UV R2RNIL to be successful in the replication of features down to 100nm. [27] The Anvik Corporation has been developing and producing UV R2RNIL systems for a number of years now and has successfully produced patterns down to one micron. [2830] Anvik has also preformed research into the large-scale production of microelectronics using R2RNIL. [7, 9, 18, 21-30] 
Of the continuous types of micropatterning processes, UV R2RNIL and thermal R2R embossing appear to yield the most promising results, and both of these processes have their own distinct advantages. In UV R2RNIL, a polymer film is coated with a photosensitive resist and placed in contact with a mold roll while simultaneously exposing the contact region to high intensity ultraviolet light, initiating a fast polymerization reaction. The film is then released from the roll with the polymer resin cured with the negative of the mold roll pattern. A number of parameters determine the quality of the pattern replication, and two important parameters to consider include the viscosity of the polymer resin and the surface energy of the mold. Resin viscosity determines the rate at which the polymer resin flows into the mold patterns. Since the resin is not pressurized or forced to flow into the mold patterns, capillary action dominates this process, and thus is greatly dependant on the viscosity of the resin. Photosensitive resins generally have a very high viscosity due to the high viscosity of the photoinitiator and monomer components of the resin. The viscosity can often be lowered by adding a solvent such as propylene glycol methyl ether acetate (PGMEA), however, as solvent concentration increases, flash evaporation occurs in the resin upon exposure to UV light, creating pattern defects. [16, 18, 25]

Mold surface energy also plays an important role in pattern replication in UV R2RNIL. Surface energy of the mold determines the adhesive force between the filmmold interface once resin curing has occurred. If the mold surface energy is too high, the cured resin will stick rather than release from the mold during the lift-off process. This often results in permanent damage to the mold since the cured resin is crosslinked and difficult to remove. Mold surface energy can be lowered by the application of a coating, 
often a fluorosilane based coating, such as heptadecafluoro-1,1,2,2-tetrahydrodecyl trimethoxysilane, which bonds to the surface of the mold and prevents interfacial adhesion between the cured resin and mold. Since thermal R2R embossing does not require the use of such surface coatings or resists, patterns can be produced easier and at a lower cost. [13, 25]

By exploiting the difference in the CTE of the metal molds used in this project and that of the thermoplastic films used as substrates, the adhesive forces between mold and substrate can be greatly reduced at the interface due to relative shrinkage of one material at the interface. As the film and mold begin to reach the end of the holding stage, the film and mold are quickly cooled by the external convection directed by the high pressure cooling air. As they cool together, the magnitude of the film shrinkage will be greater than that of the mold shrinkage, due to the difference in CTE between the two materials, thereby forcing an interfacial release. This release mechanism allows for minimal pattern damage in both the mold and the patterned film, and does not require the use of surface energy altering mold coatings that can be both expensive and difficult to properly apply. Low thermal conductivity of the film material is also desirable. During mold-film contact, it would be ideal for the mold to transfer heat to only the surface of the film, rather than conduct heat to the bulk of the film. Since the film is under tension during patterning, heating the entire film higher than its glass transition may lead to excess film stretching or tearing during operation. 


\subsection{Background}

The objective of this project is to develop a novel method for the fabrication of largearea sub-micron patterns onto a polymer substrate in a continuous thermal embossing process. A continuous embossing process will incorporate the ability to pattern features with no limit to the length dimension of a patterned area (infinite film length). The specific process involves passing a polymer film in contact with a heated mold through a pair of pressure rollers, which force the material at the surface of the polymer film to flow into the mold features. The thermal R2R embossing process is similar to that of typical thermal embossing; however, the R2R variation produces large areas of patterns in a continuous process, rather than the small areas and discontinuous patterns typical of traditional thermal embossing.

An oversimplified description of the transition between the two said embossing types would be the wrapping of the flat mold used in traditional thermal embossing around a cylinder, or roll, and using this as the new mold. A cartoon of the overall thermal R2R process is shown in Figure 1-1. In this figure, a polymer film (green) is pre-treated then fed between a pressure

roll (bottom roll, blue) and a heated embossing roll (top roller, blue). The surface of the embossing roll is patterned with the desired microfeatures to be

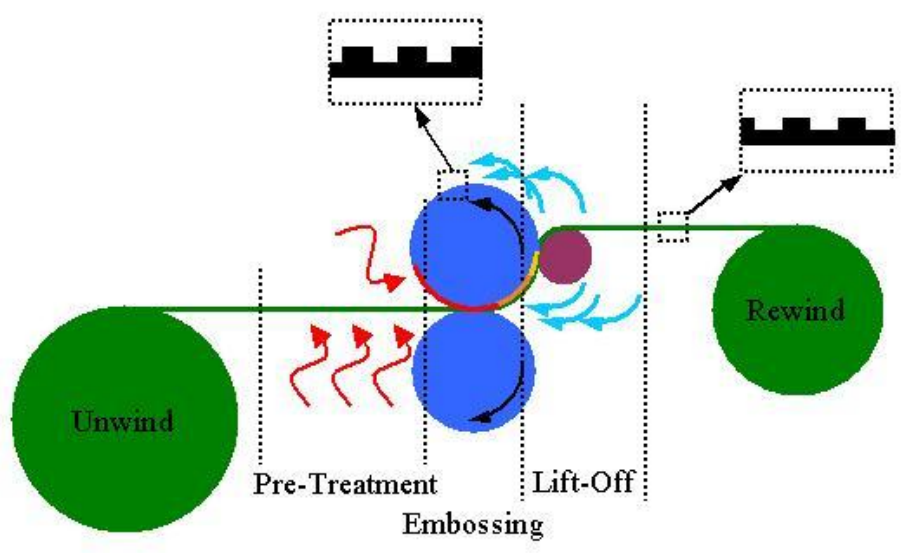

Figure 1-1: Cartoon schematic of basic R2R process. 
replicated onto the polymer film. Pre-treatment of the film may involve cleaning, corona treatment, pre-heating, or nothing at all. Once in contact with the heated embossing roll, the film is heated and pressed into the features on the surface on the roll. The film is then quickly cooled and held in the features on the embossing roll, before being lifted off.

Polymers are interesting materials unlike metals and ceramics in that they are composed of long chains of molecules grouped together. Two classes of polymer solids exist, that of thermosets and thermoplastics. Thermoplastic polymers are those that are composed of tangled macro-molecular chains. In solid form, the relatively weak Van der Waals force and the 'tangling' of a network of such large molecules hold thermoplastics together. The molecular chains may either be disordered (amorphous) or ordered (crystalline), but generally macro-molecules in thermoplastic materials are not connected to each other through covalent bonds. As such, the material exhibits viscoelastic properties, having the properties of both a liquid (viscous) and a solid (elastic). Since no covalent bonds exist between molecules in thermoplastics, they do experience a softening temperature at which they will begin to flow. [31-33]

Thermoset polymers are somewhat similar to thermoplastics except that some molecules are connected to other molecules in the network with a covalent bond. This covalent bond is referred to as a 'crosslink.' With extensive crosslinking, thermosets do not have melting points but instead will decompose if exposed to excessive heat. The two types of nanoimprint lithography cover the use of these two different sets of polymers as substrates. Embossing uses thermoplastic materials as substrates, merely pressing features into the surface of a plastic and physically forcing the material to form shape of the mold. UV curing lithography uses a thermoset-like material as a substrate, 
allowing a liquid to flow into the features of a mold and subsequently crosslinking the liquid into a solid polymer network via a photo-polymerization reaction. [32]

Figure 1-2 shows the modulus-temperature relation for polystyrene, a thermoplastic. At low temperatures, the material is in the 'glassy' regime and is strong, elastic, and brittle. The modulus remains relatively unchanged until a material property known as the glass transition temperature is reached.

The glass transition temperature is a material dependant property and is the temperature at which the motion of molecules due to heat energy in the material is enough to disrupt the Van der Waals attraction between polymer molecules. At the glass transition temperature the modulus sharply drops several orders of magnitude, as shown in Figure 1-2 for polystyrene with a

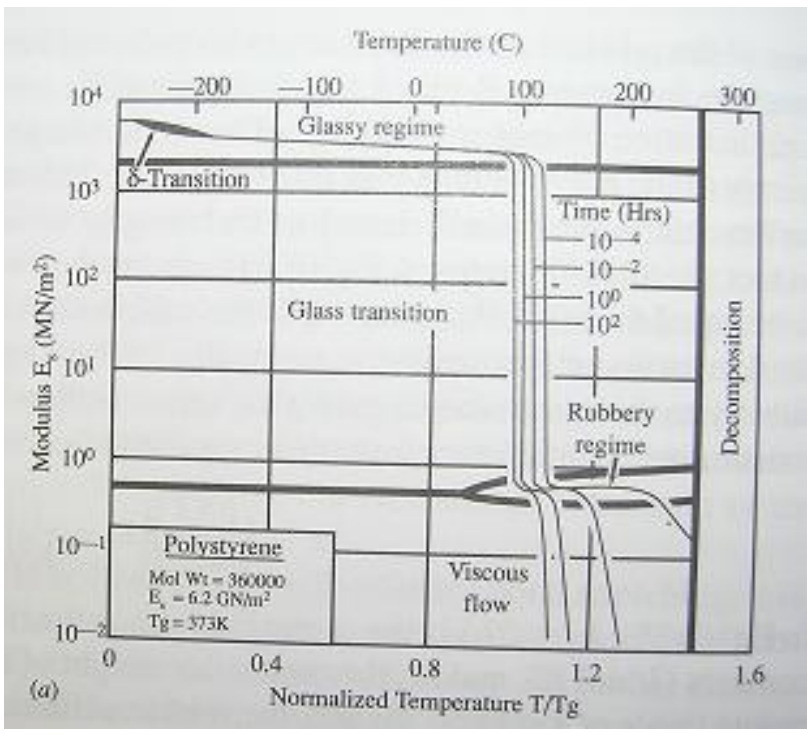

Figure 1-2: Temperature-modulus relationship for Polystyrene $(\mathrm{Tg}=$ $\left.100^{\circ} \mathrm{C}\right)$. glass transition temperature of $100^{\circ} \mathrm{C}$. By heating the polymer higher than that of the glass transition temperature, it should become much more like a viscous liquid. Simulations preformed by Young have shown that for temperatures much higher than the glass transition temperature of the material no elastic effects (relaxation) are observed. [31-34] 


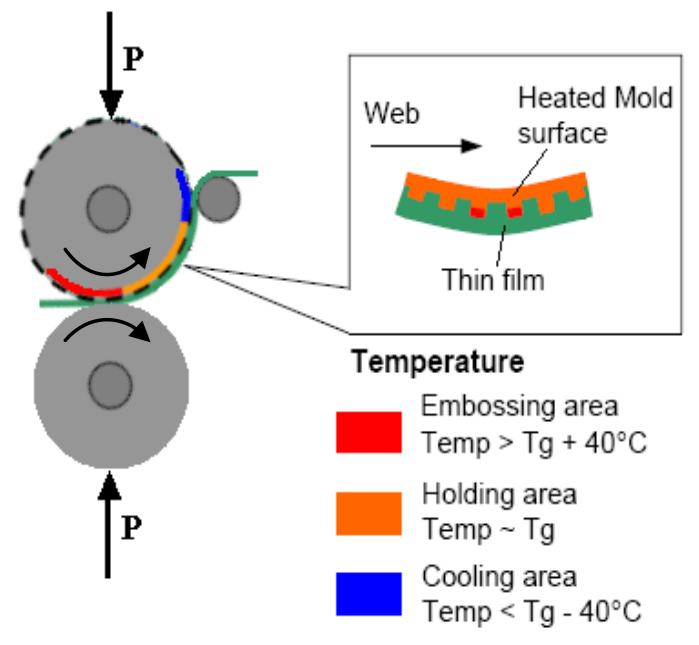

Figure 1-3: Embossing stage of $\mathrm{R} 2 \mathrm{R}$ showing temperatures in their respective areas.
Target temperatures achieved at specific locations during the embossing process are shown in Figure 1-3. This cartoon shows the film (green line) entering the embossing region, where the surface of the embossing roll (top roll) has been heated to $40^{\circ} \mathrm{C}$ above its glass transition temperature (red, top roll). Increasing the film temperature beyond the glass transition temperature is critical, as

the elastic modulus of the substrate quickly drops once this temperature is exceeded. A semi-log plot of the elastic modulus (tensile modulus) versus temperature for PET is shown in Figure 1-4. [35] At the glass transition temperature of PET $\left(\sim 80^{\circ} \mathrm{C}\right)$ the elastic modulus begins to drop off more steeply with temperature until hitting its melting point where it looses much of its elastic properties. $[34,35]$

Temperatures in the holding regime of the embossing step will typically be just around the

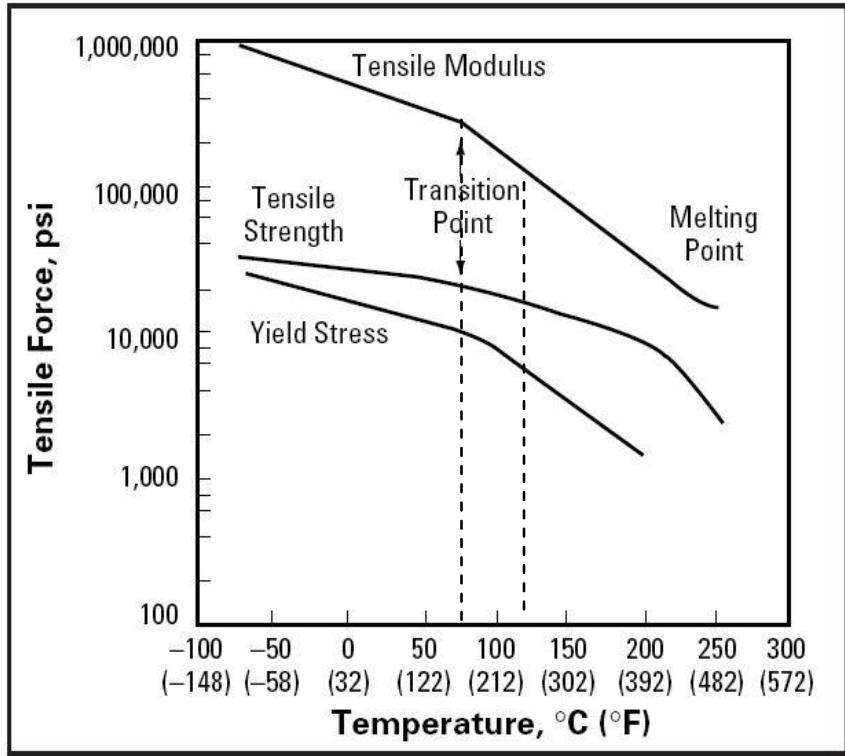

Figure 1-4: Tensile properties of a similar PET material used in this project. 
glass temperature of the material (orange, top roll). This holding stage is an important part of the embossing process, especially when using thermoplastic materials, as relaxation effects can become a problem. Relaxation is a viscoelastic effect wherein a plastically deformed polymer will creep, or relax, to its undeformed shape after the load has been removed. This often occurs on the timescale of hours to days after unloading. The mechanism for this effect is the partial mobility of polymer chains within a network. Rather than move from one location to another in a polymer network when stressed, a polymer chain may only stretch elastically and form new entanglements in this stretched position. Immediately after the load is removed, the polymer chain will not immediately recover its elastic strain because of the entanglements, and net plastic strain in the bulk material will be observed. Since elastic strains will still exist within the polymer chain (assuming the chains have not been broken), the chain will attempt to recover this strain, however slowly, since entanglements with other chains will hinder this recovery. This has been directly observed in embossed features. Relaxation can be reduced by allocating sufficient holding time, allowing for freezing of the polymer in its deformed state; and also by embossing at a sufficiently high temperature, inciting maximum mobility of the polymer chains when loaded. Once the temperature in the film has been lowered to well below its glass transition temperature $\left(40^{\circ} \mathrm{C}\right.$ or more below) it is lifted off the embossing roll. [18, 33, 36, 37]

This project has been split into three phases: Machine Design, Mold Design, and Experimentation. The Machine Design phase encapsulates the design, assembly, and testing of a stand-alone machine which will be capable of producing the desired product. Proper control of film speed, embossing pressure, embossing temperature, along with 
optimized machine geometry, and heating and cooling systems will be the foundations to success in this project.

Once a proper machine has been constructed, a mold design must be incorporated into the system for the transfer of the desired features. The objective of this phase is to create a mold capable of producing features continuously, not necessarily to produce continuous features, although this would be ideal. The logistics of creating a circular mold with nano- or even microscale features that matched seamlessly is not the focus of this project. The mold design to be developed in this project is that of a belt type mold resembling a conveyor belt.

The experimentation phase encompasses the both the experimental and simulation aspects of this project. Work done during this phase will include material selection, machine tuning, physical experimentation, and the characterization of the patterns produced. Certain material properties of the films used for substrates are of great importance during the embossing process, these properties include the following: coefficient of thermal expansion (CTE), glass transition temperature $\left(\mathrm{T}_{\mathrm{g}}\right)$, and thermal conductivity. An optimization of the process parameters will be necessary to not only provide good output efficiency but is also required to achieve any success at all. A good example would be choosing a proper film speed, as this will greatly affect the heating and cooling requirements of the mold and film.

Since this is to be a continuous process, it is clear that the net heat transfer into the embossing roll per cycle must be identically zero to avoid overheating of the mold. While it may be an easy task to quickly dump heat into the embossing roll to achieve necessary embossing temperatures, it is not so easy a task to remove such large amounts 
of heat within one cycle. In this project, the heat generation in the mold will be accomplished using the Rapid Thermal Response (RTR) method, pioneered by Kim and Yao at the University of Massachusetts Amherst. [38, 39] The RTR method uses induction heating as the heat source, and thin sections of a mold are heated, often with undercuts for the reduction of the thermal inertia of the surface to be heated. RTR has been proven to raise the temperature of a mold to $250^{\circ} \mathrm{C}$ in 2 seconds. Cooling methods considered in this project focus on external convection as the primary source of heat removal; however, a design for an internally cooled roller is also discussed. [38, 39]

A partner in this project, Professor Donggang Yao of the School of Polymer, Textile \& Fiber Engineering at Georgia Institute of Technology, will perform the simulations of polymer flow into the mold during embossing. The process performed in this experiment can be modeled in a way similar to that of an injection molding process, with viscous polymer forced to flow into the vacancies in a mold. Obtaining measurements needed for proper simulation will also be part of this phase of this project. Characterization of replicated features will be accomplished by scanning electron microscopy, optical microscopy, profilometry, and atomic force microscopy, where applicable. 


\section{CHAPTER 2}

\section{MACHINE DESIGN}

\subsection{Base Machine}

The foundation of this project is the design of the machine used in the embossing of the microfeatures. A poorly designed embossing machine will result in poor replication quality, wasted time, and an overall sense that R2R embossing cannot be accomplished in this manner; therefore the success of this project largely depends on the quality of the machine design. The first step in considering a proper machine design will be a clear understanding of the R2R process.

A Stanat roll press was obtained and used as the core of the embossing stage: the embossing roll and pressure roll. A picture of the working section of this machine is

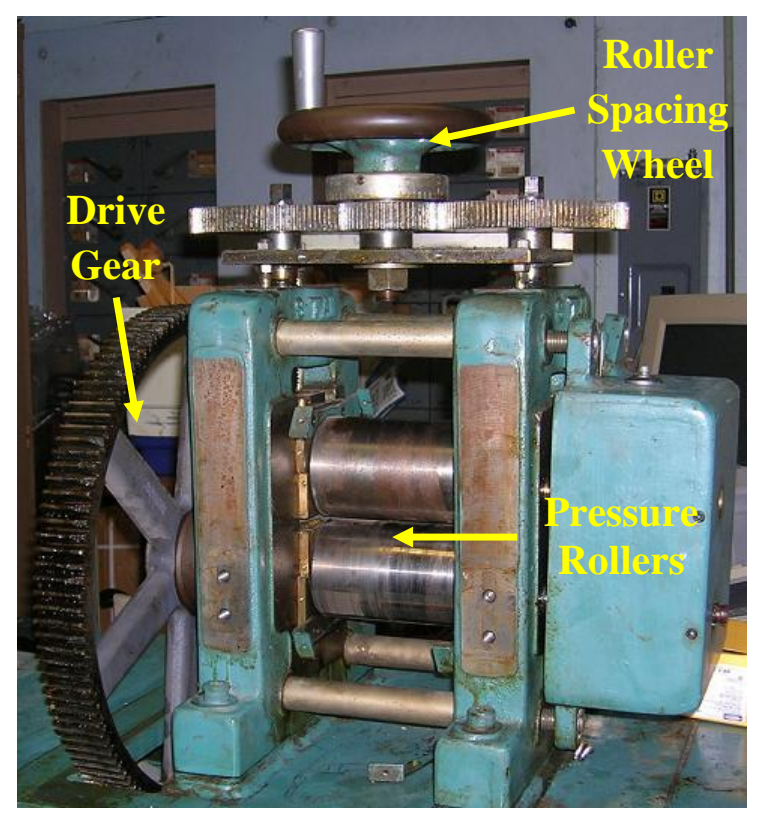

Figure 2-1: Working section of unmodified Stanat roller press used as base machine for embossing. shown in Figure 2-1; the embossing roll (top) and pressure roll (bottom) are driven by a 3 hp motor. A screw-type bearing mount sets the displacement of the top roller relative to the bottom roller; rotating the wheel on top of the machine changes this value. The rollers are $76 \mathrm{~mm}$ in diameter. There is no system of measuring applied force with the base machine, but it is assumed the maximum force that can be applied is 
quite large. This is based on the hefty brass mounts, through-hardened steel rollers, $13 \mathrm{~mm}$ diameter steel displacement screws, and the fact that this machine is typically used to cold roll steel bar stock. A method for measuring applied force during experimentation is discussed later. This roll press will also serve as the primary driving

motor for the roll-to-roll system. The base Stanat roll press is equipped with a 4 -speed transmission, and even running in the lowest gear the roller speed was much faster than desired. To remedy this problem, a GE Fuji AF-300 Mini electric frequency drive was added in-line to the power supply of the Stanat machine, which created the ability to select the desired speed (between 0 and maximum speed).

\subsection{Induction Heating}

The process of induction heating uses a high frequency current running through a copper coil to primarily induce eddy currents in the surface of the heated part. The electrical resistance of the material to the eddy currents then heats up these areas, and this is referred to as Joule heating. Induction heating obeys Maxwell's four laws of electromagnetism:

$$
\begin{gathered}
\nabla \cdot D=0 \\
\nabla \times H=J+\frac{\partial D}{\partial t} \\
\nabla \cdot B=0 \\
\nabla \times E=-\frac{\partial B}{\partial t}
\end{gathered}
$$


Where $\mathrm{D}$ is the electric flux density, $\mathrm{H}$ is the magnetic field intensity, $\mathrm{E}$ is the electric field intensity, $\mathrm{J}$ is the current density, and B is the magnetic flux density. The Joule heat (Q) induced in a region of a part can be calculated using the material's electrical resistivity $(\rho)$ and the current density J:

$$
Q=\frac{1}{2} \rho J^{2}
$$

During induction heating, the current density $\mathrm{J}$ varies exponentially with the depth into the part,

$$
J=J_{S} e^{-d / \delta}
$$

Where $\mathrm{J}_{\mathrm{S}}$ is the current density at the surface of the part, $\mathrm{d}$ is the depth below the heated surface, and $\delta$ is the characteristic length, also known as the skin depth. Induction heating is most well known for this tendency to heat the surface of a part; this is known as the skin effect. The skin depth is the depth in which $63 \%\left(1-\mathrm{e}^{-1}\right)$ of the heating occurs, and is calculated through the following formula:

$$
\delta=\sqrt{\frac{\rho}{\pi f \mu_{r} \mu_{0}}}
$$

Where $\rho$ is the electrical resistivity of the heated material, $f$ is the AC current frequency, $\mu_{\mathrm{r}}$ is the relative magnetic permeability of the heated material, and $\mu_{0}$ is the magnetic constant. In addition to Joule heating, magnetic materials are also affected directly by the magnetic fields created by the changing electric current. In hysteresis heating, the dipoles within the material are jostled by the applied magnetic field, which heats the 
material through internal friction from this motion. In this project, it is only desirable to heat the surface of the mold, the protruding features, in order to allow the polymer substrate to flow and emboss properly. Excess bulk heating of the mold will only complicate the cooling process after embossing is complete, therefore the skin depth should be minimized. [40, 41]

The skin depth is inversely proportional to the square root of current frequency and magnetic permeability of the material; and is directly proportional to the square root of the electrical conductivity of the material. Generally, when heating parts using induction heating, there exist few frequencies that will allow for proper current flow within the part. These 'resonant' frequencies depend heavily on the geometry of the part (mold) and the coil, but also on the material and the mass of the part. Therefore it will be advantageous to use the highest resonant frequency available for experimentation. The skin depth is also inversely proportional to the magnetic permeability of the material. A non-magnetic material has a magnetic permeability of $1[\mathrm{Henry} / \mathrm{m}]$, and most magnetic materials such as the magnetic steel and nickel alloys have a magnetic permeability in the range of 500 $1300[\mathrm{H} / \mathrm{m}]$; therefore a mold composed of such a material will have a much more shallow skin depth when compared with its non-magnetic counterparts. Additionally, the use of a magnetic mold material will allow for hysteresis heating. Although it may be tempting to lower electrical resistivity in order to further reduce the skin depth, the joule heating created by the eddy currents in the surface of the part is proportional to the resistivity from equation (1.5), therefore the resistivity is not used as a design variable in the optimization of the skin depth. [42, 43] 
The induction heating unit used in this project is an Ameritherm Novastar 20kW unit with a maximum AC current frequency of $485 \mathrm{kHz}$. An oval shaped three-turn closedloop induction heating coil with a major axis diameter of $89 \mathrm{~mm}$ and a minor axis diameter of $28 \mathrm{~mm}$ was used for its convenience and ideal shape for heating molds moving through the coil. The surface of the coil was coated in an electrically insulating paint that prevented arcing between turns of the coil, and between the coil and workpiece.

\subsection{Pre-Heating}

It is not expected that the brief contact between the hot mold and cold film substrate will be enough to transfer the heat required to raise the surface of the film above its glass transition temperature; therefore it should be necessary to pre-heat the film before the embossing stage. The method for pre-heating in this project takes advantage of the ultraviolet absorption of many polymer films, which is usually an undesired in photolithographic processes since this leads to excess heating and

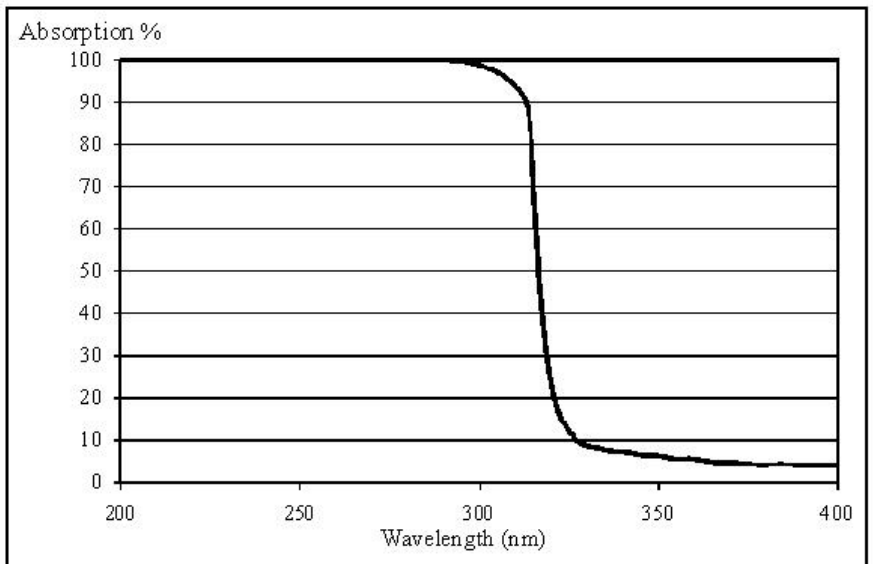

Figure 2-2: Absorption spectrum of PET film used for embossing experiments warping in the film. The absorption spectrograph (wavelength vs. absorption \%) of the polyethylene terephthalate (PET) film $(0.2 \mathrm{~mm}$ thickness) used in experimentation is shown in Figure 2-2. The spectrograph shows full absorption of light under $\sim 300 \mathrm{~nm}$ and nearly full transmittance of light above $\sim 330 \mathrm{~nm}$. PET is well suited as a substrate for the 
embossing due to its ideal mechanical and thermal properties. This spectrograph shows the complete absorption of electromagnetic radiation with a wavelength under about 300nm. UV light was chosen as the pre-heating method in this project since a UV light source has already been aquired as part of a prior project.

In order to properly control this heating process, a brief experiment was performed to determine the generated heat. The UV emitter used was a Fusion UV Systems F300S system, with an output spectrum as shown in Figure 2-3; the ordinate plots the radiated power $\left[0-80 \mathrm{~W}-(10 \mathrm{~nm})^{-1}\right]$ against the wavelength $(200-600 \mathrm{~nm}) . \quad$ Three exposure trials were made, as shown in Figure 2-4, and are the following: one exposure with a bare thermocouple (blue curve), one exposure with a thermocouple covered by a PET

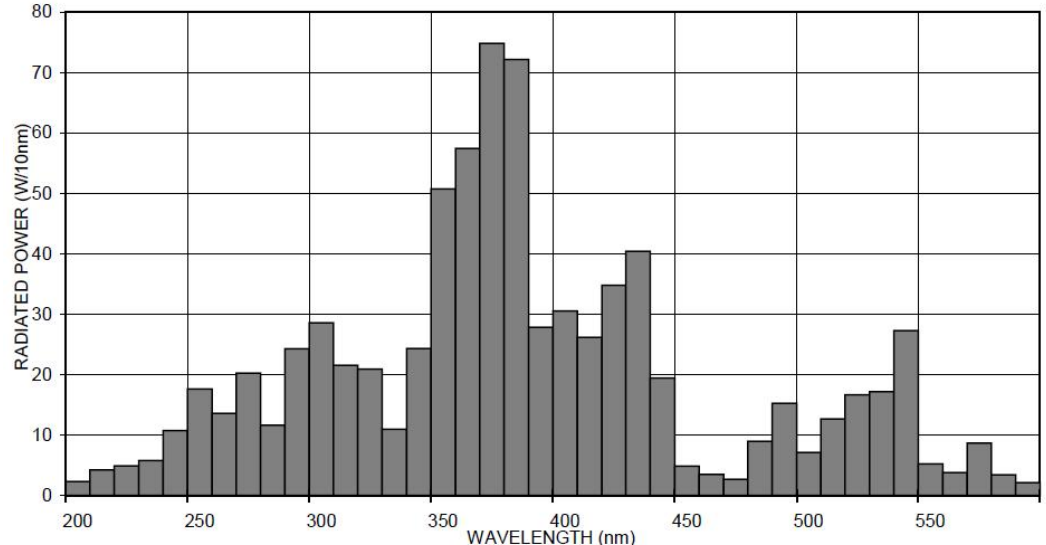

Figure 2-3: Emission spectrum of UV light used as preheating source.

film but not in contact with the film (green curve), and one exposure with the thermocouple fixed to the underside of the PET film (red curve). Upon comparison of the blue and green curves, where the blue curve represents the heating response of the isolated thermocouple and the green curve represents the heating response of the PET covered thermocouple, it is obvious that much of the emitted UV radiation is absorbed by the PET film. Some excess radiation, whether UV or that of higher wavelength, does penetrate the PET film and heats the thermocouple. The temperature response of the PET 
covered thermocouple (green curve) reveals that this excess radiation heats the thermocouple to a temperature of $232^{\circ} \mathrm{C}$. [16]

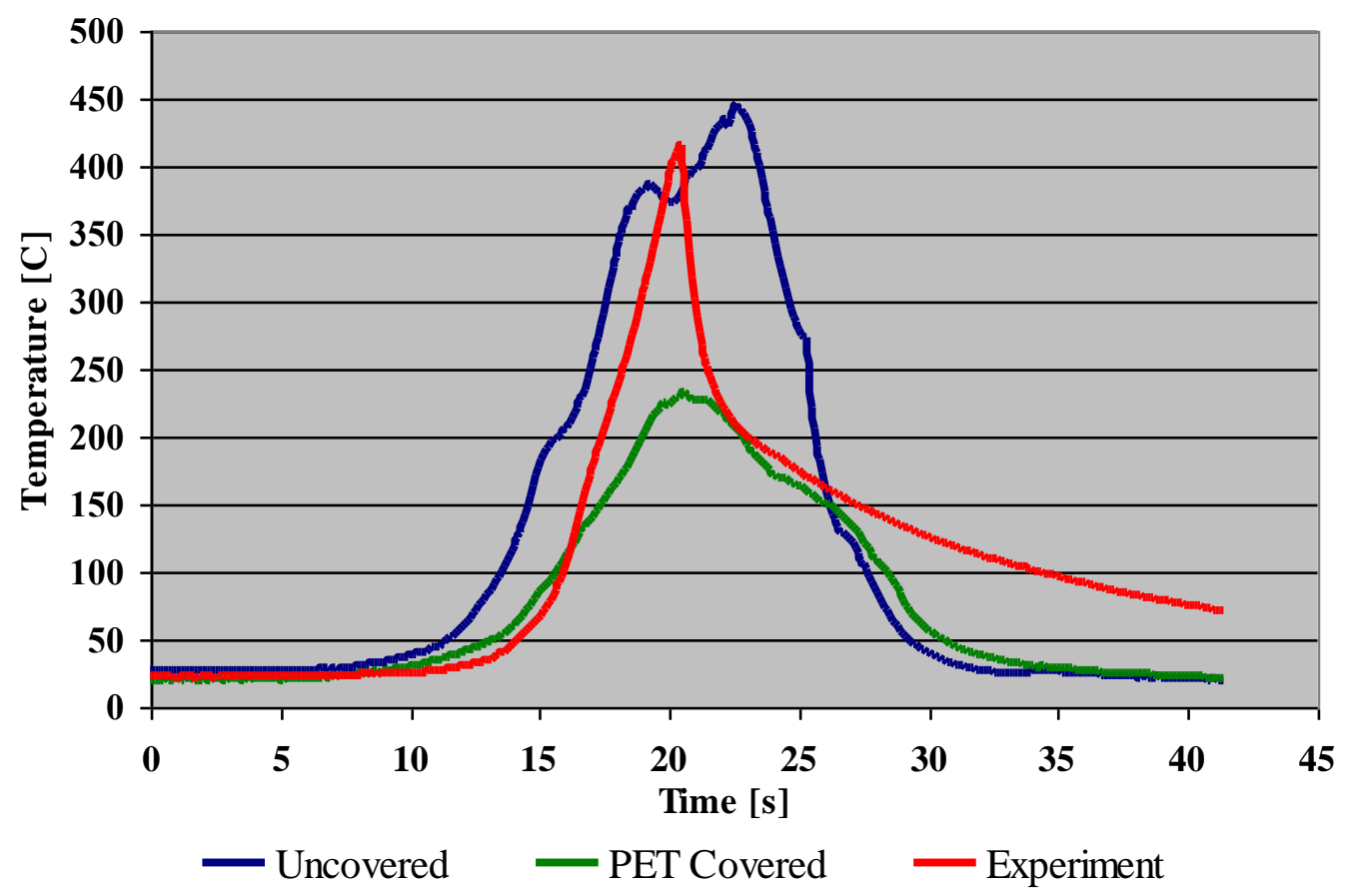

Figure 2-4: Temperature response of PET film and thermocouple under UV light.

When the PET film covering is brought into contact with the thermocouple during a $\mathrm{UV}$ exposure test (red curve), the temperature reaches a maximum of $415^{\circ} \mathrm{C}$. Since the maximum temperature the thermocouple can reach by excess radiation alone when covered with a PET film is $232^{\circ} \mathrm{C}$, the measured film temperature can be taken as an accurate representation of the actual film temperature. The melting temperature of PET is only $265^{\circ} \mathrm{C}$, and indeed, severe warping and holes were observed during the heating of the film. From the slope of the red curve in Figure 2-4, we can obtain a temperature rise per time of the PET film when exposed to this particular UV source, which is graphically calculated to be $62\left[{ }^{\circ} \mathrm{C} / \mathrm{s}\right]$. This is a sufficiently fast heating rate and in fact an adjustable, 
UV-absorbing pyrex plate has been incorporated over the UV system to absorb some of the emitted radiation. [32]

\subsection{Cooling}

In order to prevent overheating during continuous operation, the net heat added per cycle must be equal to zero; therefore a proper cooling system is of high importance. The majority of the cooling in this project will be accomplished using external convection in

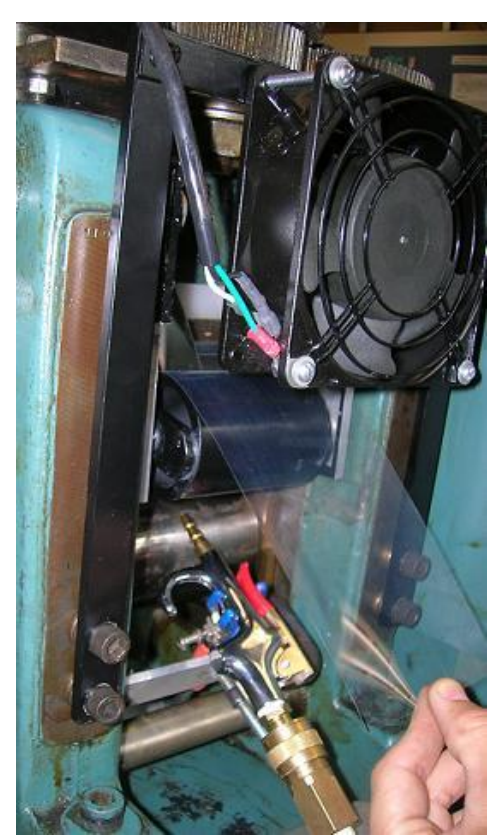

Figure 2-5: Backside of the embossing machine. the form of both high-pressure compressed air and ambient air. Compressed air at 80psi is blown over the PET film and mold during the holding stage of embossing. Once lift off has occurred, a cooling fan channels ambient air over the top of the embossing roll, cooling the mold. The blue arrows shown previously in Figure 1-1 illustrate both modes of cooling. Figure 2-5 shows a picture of the backside of the R2R embossing machine, showing the cooling fan.

Additionally, a design for an internally cooled embossing roll has been developed. It is expected that a large amount of heat will be transferred to the embossing roll from the mold; therefore an internally cooled embossing roll will provide the necessary heat removal to keep the embossing roll at a steady temperature. This design, a CAD model of which is shown in Figure 2-6, incorporates a mold sleeve that slides over the modified embossing roller and is locked into place by a key. Figure 2-6(c) shows the flow of cooling air through the 
central supply hole to the 15 cooling slots distributed equally about the circumference of the embossing roll under the sleeve. The supply hole is threaded to an air chuck that can be connected to compressed air.
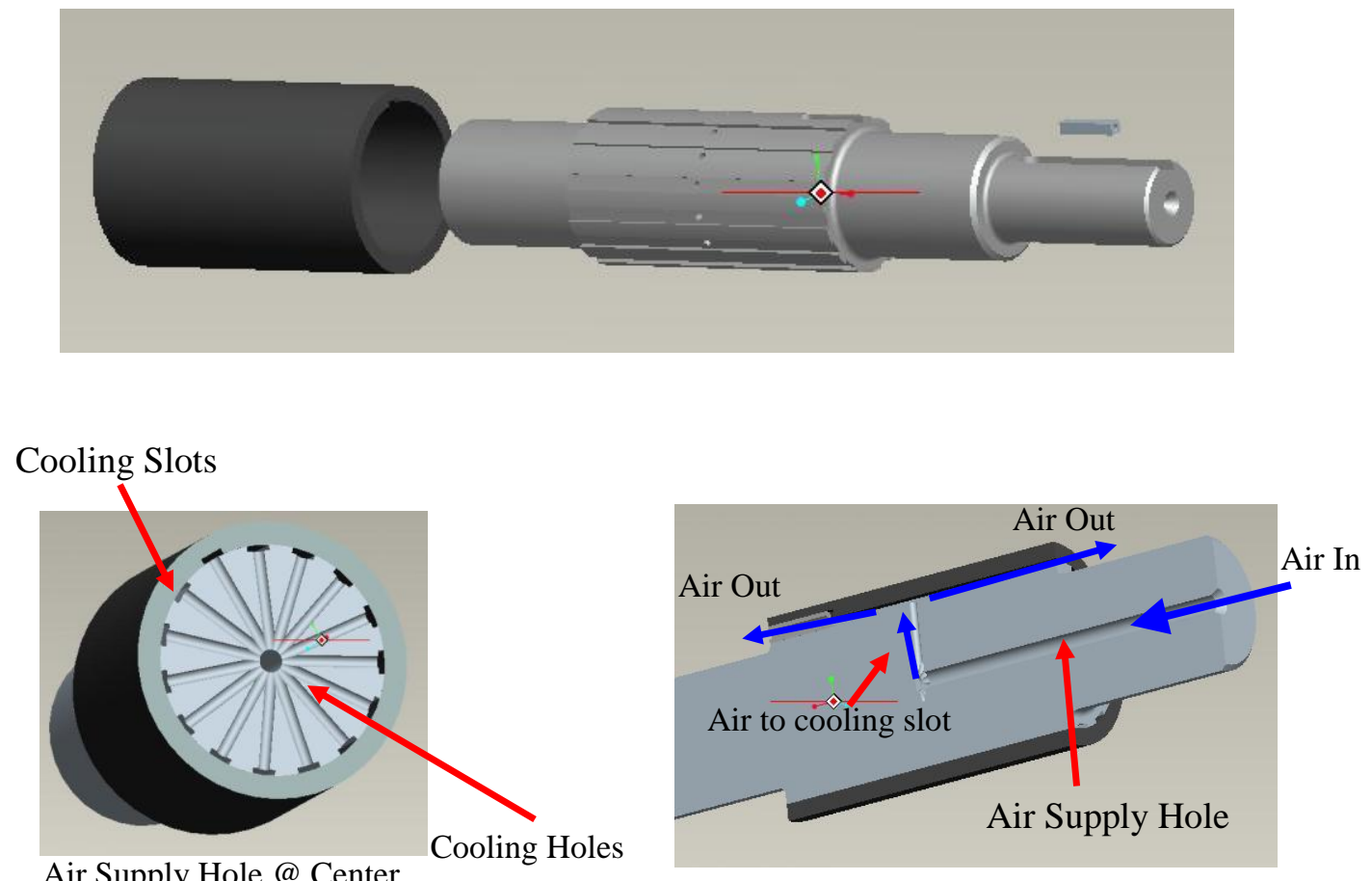

Figure 2-6: Embossing roll assembly; exploded view (a), transverse center $x$ section (b), and parallel x-section showing flow of cooling air (c). 


\section{CHAPTER 3}

\section{R2R MOLD DESIGN}

\subsection{Mold Geometry}

As previously mentioned, the mold design that will be developed in this project is that of a looped conveyor-type mold. This transition is shown in Figure 3-1. The primary basis for this decision is the superior heat transfer properties this type of mold will

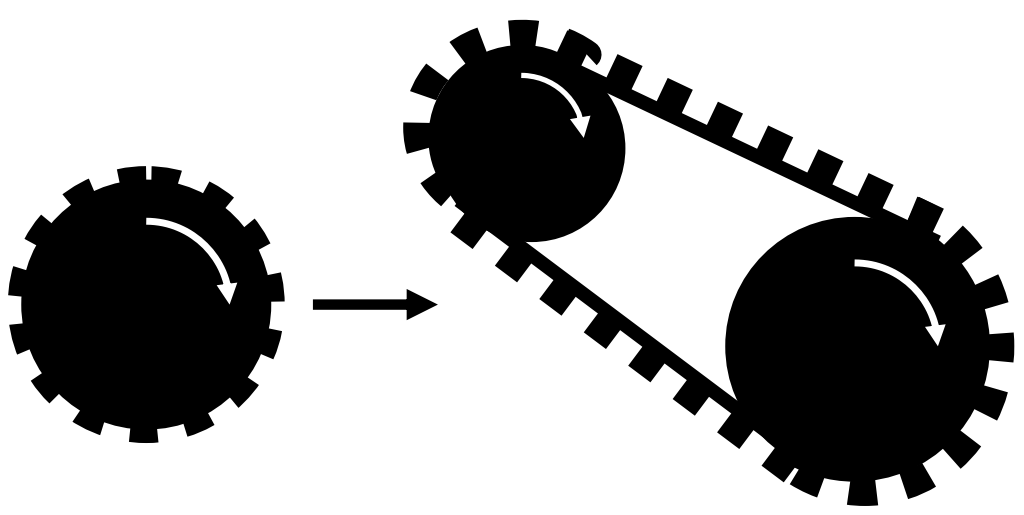

Figure 3-1: Transition from circular R2R mold to conveyor R2R mold. provide to the system; the first of which will be the maximizing of the induction heating efficiency by allowing the mold to actually move through the induction heating coil, rather than

over it, as is the case when the mold is attached to the embossing roll. The increased surface area from having both a longer mold, and exposing both sides of the mold when it is detached from the embossing roll effectively doubles the heat transfer provided by external convection. A second advantageous effect of using a conveyor mold is that of the inhibited size constraint of the mold. When simply wrapping a mold about a cylinder, the length of the continuous mold is limited to the circumference of the mold, but when a conveyor mold is used the continuous mold length is no longer limited by this constraint and can be made as long as desired. 
A cartoon diagram of the $\mathrm{R} 2 \mathrm{R}$ embossing process using a conveyor mold is shown in Figure 3-2. In this figure, Dark blue circles are pressure rolls, purple rolls are idler rolls, film is dark green line and circles, and cooling air represented with light blue arrows. Red wavy arrows could represent corona treatment, heat, or other types of pretreatment used in embossing techniques. The black loop surrounding the embossing roll (top blue circle) is the mold; it is shown wrapped around the conveyor roll and moving through the

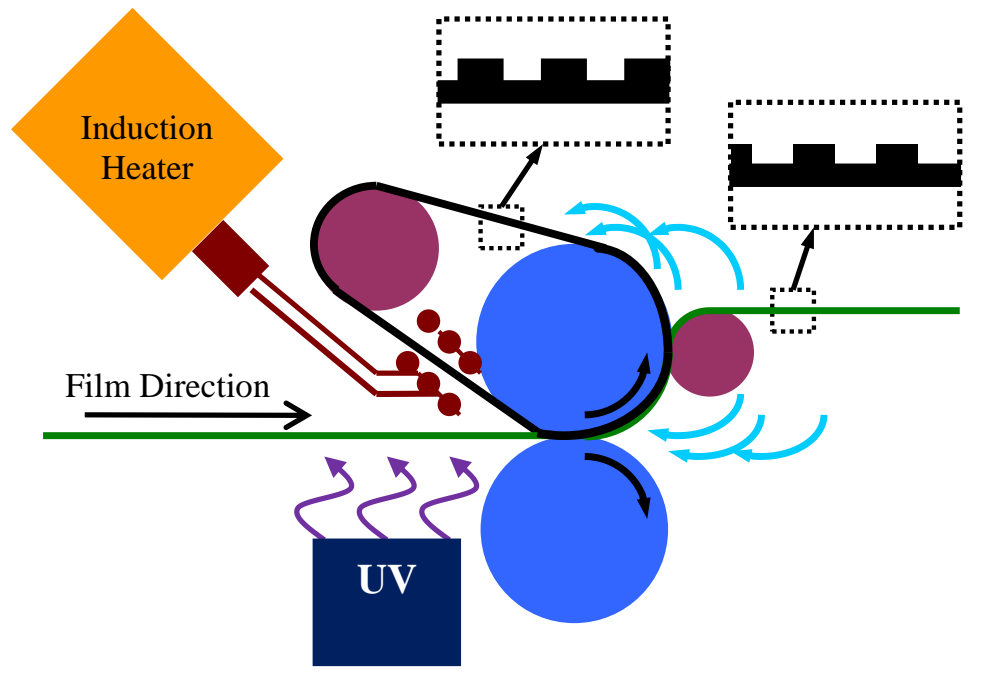

Figure 3-2: Cartoon cross-sectional view of proposed embossing process.

induction heating coil. The initial mold used is in the form of two $290 \mathrm{~mm} \times 25 \mathrm{~mm}$ 'ribbons' attached by a polyimide-based adhesive that is tolerant of temperatures up to

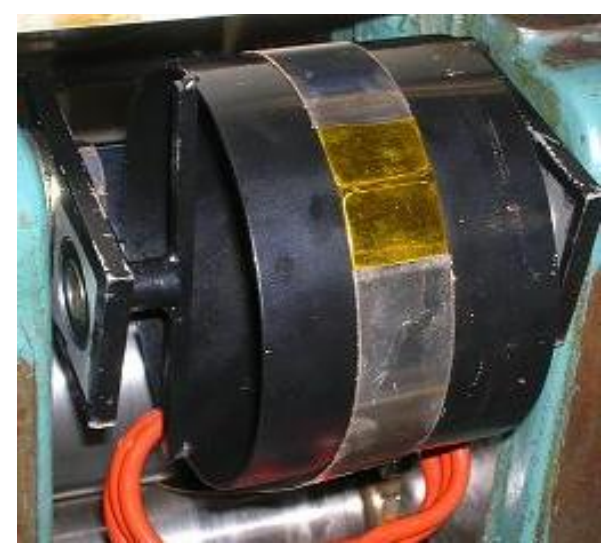

Figure 3-3: Adhesive connection between mold ribbons. $250^{\circ} \mathrm{C}$. The mold strips were wrapped into the required elliptical shape and layers of adhesive applied to the inner diameter of the mold strips. A picture of the adhesive connection between mold strips is shown in Figure 3-3. In this figure, the black roll is the conveyor roll, the silver strips are the mold ribbons, and the orange film between the mold ribbons is the adhesive. The mold strips 
were wrapped into the required elliptical shape and layers of adhesive were applied to the inner diameter of the mold strips to ensure a constant mold thickness throughout the conveyor mold.

\subsection{Mold Features}

The mold initially used for experimentation was a nickel alloy mold with sawtooth type features $30 \mu \mathrm{m}$ in height and pitch. This is a flexible mold, being only $230 \mu \mathrm{m}$ thick. A drawing of the cross-section of the mold is shown in Figure 3-4. The flexibility allows

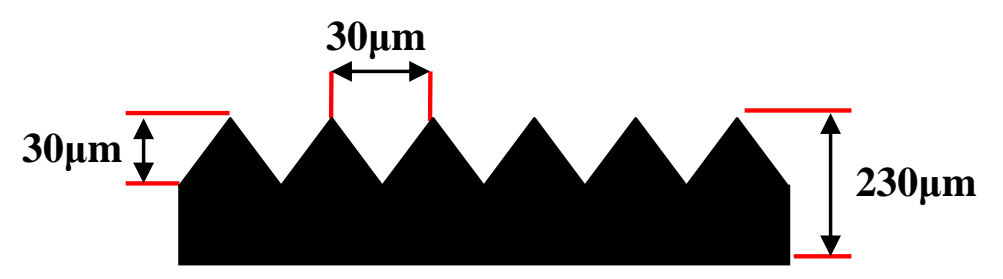

Figure 3-4: $30 \mu \mathrm{m}$ sawtooth mold features in nickel. for the mold to be looped around the embossing roll and a dummy roll that simply redirects the mold back to the embossing roll. The small thickness of the mold may raise questions about its ability to be heated efficiently using induction heating. For efficient induction heating of rectangular cross-sections it is generally required that the heated part be at least two times the skin depth in thickness (to allow for unobstructed eddy current flow). The relative magnetic permeability of the mold material (nickel) is $1240[\mathrm{H} / \mathrm{m}]$ and the electrical resistivity is $6.4 \mathrm{e}-8[\Omega-\mathrm{m}]$. The induction heater was tuned using a section of this mold, and the highest resonant frequency the machine could produce was found to be $231 \mathrm{kHz}$. Inserting these values, and the magnetic constant of $4 \pi \times 10^{-7}[\mathrm{H} / \mathrm{m}]$, into equation (1.7) a skin depth of $7.52 \mu \mathrm{m}$ is calculated, and the mold thickness used here is confirmed to be well above the two-skin-depth requirement. [42, 43] 
Six molds in non-conductive substrates were also acquired for embossing experiments. Since the following molds are all non-conductive and non-magnetic, they require electroforming with a magnetic metal. The first of these molds is a $250 \mathrm{~nm}$ linewidth $375 \mathrm{~nm}$ period grid a feature height of $200 \mathrm{~nm}$ on a poly(methyl methacrylate) (PMMA) substrate and was made using a traditional nanolithography process. The second mold is a $500 \mathrm{~nm}$ line grid color filter. This mold was produced using laser interference lithography and produced a 'stepped' line pattern. The film with this pattern is known as a 'colorless' color filter because no pigment has been added to absorb any spectrum of light; the light is filtered solely by the refractive properties of the surface pattern. The substrate of this mold is unknown, but assumed to be PET or a similar material. [10-12]

The third mold is a grid of lines with a $700 \mathrm{~nm}$ period and $300 \mathrm{~nm}$ linewidth set in ethylene tetrafluoroethylene (ETFE). This mold was obtained from Professor L. J. Guo at the University of Michigan Ann Arbor. Professor Guo provided us with a piece of mold he has been using in his UV R2RNIL experiments in which he demonstrated that the process is capable of replication of patterns down to 100nm. [27]

Two of the molds used were obtained from Professor Russell's group at the University of Massachusetts Amherst in the Department of Polymer Science and Engineering. The features obtained are $25 \mathrm{~nm}$ and $35 \mathrm{~nm}$ cylindrical posts composed of silicon dioxide. The method of production for these nanofeatures involved the selective removal of one phase of a diblock copolymer, filling of the recesses with poly(dimethyl siloxane), and subsequent plasma etching. [44, 45] 
The last non-conductive mold acquired was a circuit test pattern in an acrylate based photoresin on glass. Professor Carter's group at the University of Massachuestts Amherst in the Department of Polymer Science and Engineering provided the pattern. The pattern is composed of lines of various lengths, from $1 \mu \mathrm{m}$ down to $250 \mathrm{~nm}$, and nanocircuitry on which to test pattern continuity using a 4-point probe or other electronic circuit-measuring device.

\subsection{Electroforming Background}

Electroforming is a process by which metal is deposited on the surface of a substrate, or mandrel. Often used for its excellent surface finishes and ability to create uniform parts of varying thickness, electroforming has more recently been incorporated into the nanofabrication industry. Electroforming is preformed by running a current through a positive anode "target" and a negative cathode, or mandrel, in an aqueous ionic solution. The target is composed of the pure metal or alloy desired in the final product, and the mandrel is the mold around which the metal is deposited. Many different pure metals and alloys can be electroformed. A schematic of the nickel electroforming process is shown in Figure 3-5. In this figure, a non-conductive mandrel (a) is vapor coated with a conductive 'seed layer' (b) to produce a mandrel with a conductive surface (c). The mandrel, along with a target material, is then placed in an aqueous solution of metallic and non-metallic ions known as a Watts bath (d). The target (positively charged block) is attached to the positive end of a current source and the mandrel (negatively charged circle) is connected to the negative terminal of the current source. A typical Watts bath for a nickel electroplating solution is composed of nickel sulphate $(240-360 \mathrm{~g} / \mathrm{l})$, 
sodium chloride (15-30 g/l), boric acid (30 - $45 \mathrm{~g} / \mathrm{l})$, and often wetting agents and/or surfactants are added to improve surface quality in the finished part. [46-48]

(a)
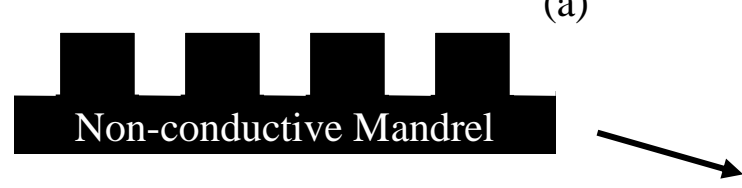

(c)
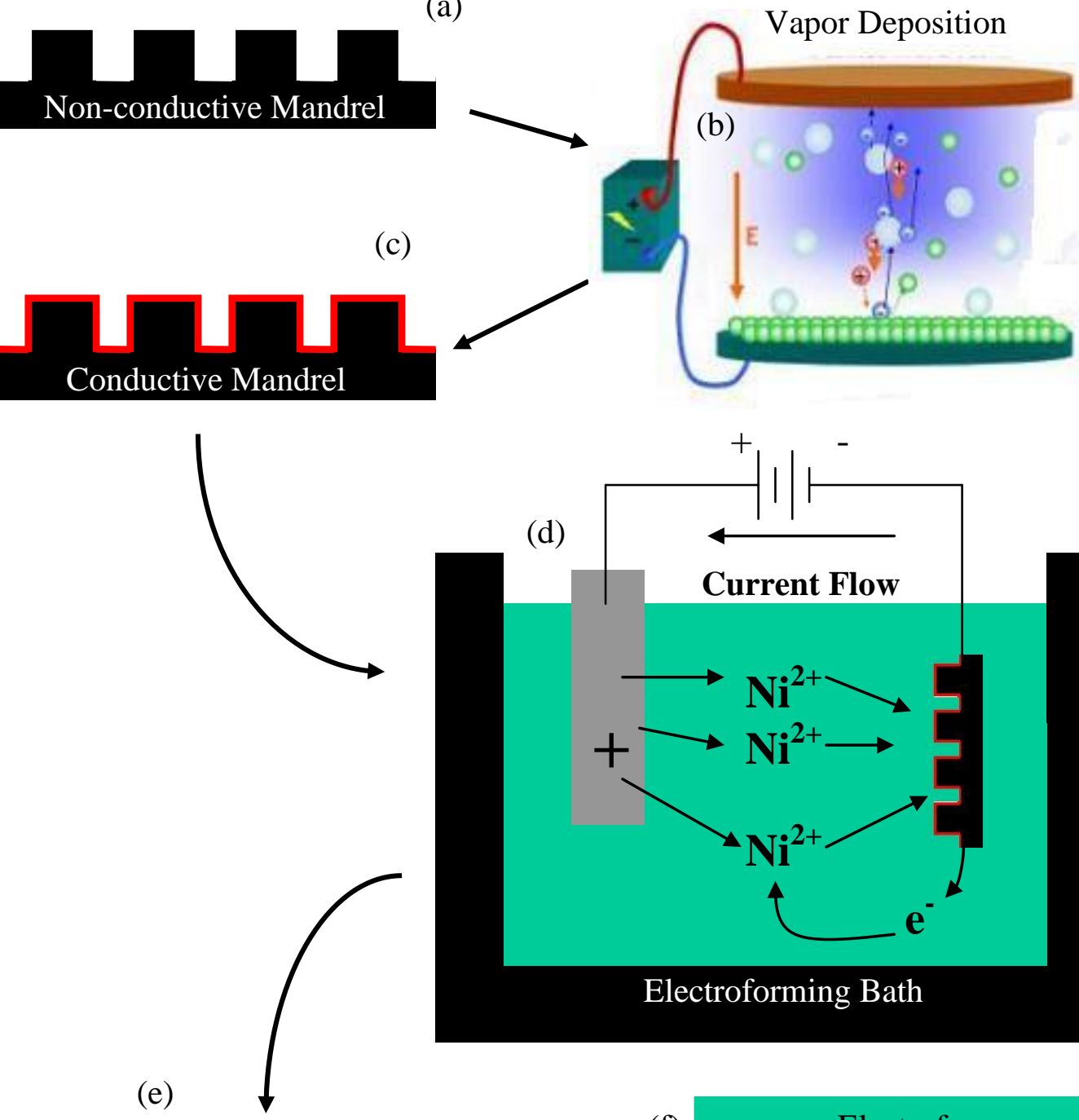

\section{Electroforming Bath}
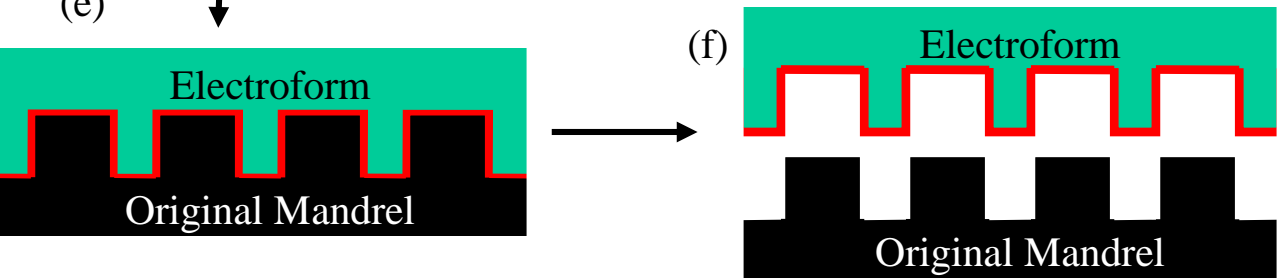

Figure 3-5: Overview of the process required for electroforming of a nonconductive mandrel (mold). 
As a voltage difference is generated between the anode (target) and cathode (mandrel) the positively charged nickel ions $\left(\mathrm{Ni}^{2+}\right)$ become attracted to the mandrel and the negatively charged sulphate ions $\left(\mathrm{SO}^{4-}\right)$ become attracted to the target. Electrons from the mandrel are combined with the nickel ions and chemical bonds are formed with the surface of the mandrel and nickel. Nickel ions are replenished into the solution from the target. Once completed, the mandrel is then removed from the Watts bath Figure 3-5(e) and the electroform and mandrel are separated (f). Microstructure, surface quality, and internal stress of the finished product can be accurately controlled by tuning solution $\mathrm{pH}$, current density, alloying concentration, bath temperature, and other parameters involved in the electroforming process. [46-48]

\subsection{Mold Replication}

The electroforming mandrel is the mold or form used to deposit the metal in a desired shape and may be composed of both conductive and non-conductive substrate materials. The molds used as mandrels in this project are all composed of non-conductive mandrels, therefore a metallic coating must be deposited on the surface of the mandrel prior to electroforming to produce a conductive surface upon which metal can grow. This is often done by treating in a silver bath (silvering), or by vacuum/sputter coating gold or palladium onto the surface of the mandrel. Good adhesion between the non-metallic surface and the conductive surface is needed to achieve proper replication. 
Due to the number of molds to be replicated via the electroforming process, and the cost of surface metallization, it is desired to combine all the molds into one mandrel. A $150 \mathrm{~mm}$ diameter polycarbonate disc was used as the base for the combined mandrel and a recess for each mold was machined into the surface of the disc to keep the surface of the mandrel as level as possible. Each mold was set into its respective recess and a twopart epoxy was used to secure the molds to the mandrel. A picture of the finished mandrel prior to electroforming is shown in Figure 3-6. In this figure, the mold material and patterns clockwise from top are as follows: 250nm lines in PMMA, 500nm lines in PET, 300nm lines in ETFE, 35nm posts in silicon dioxide, 100-1000nm lines in acrylic resin, and $25 \mathrm{~nm}$ posts in silicon dioxide.

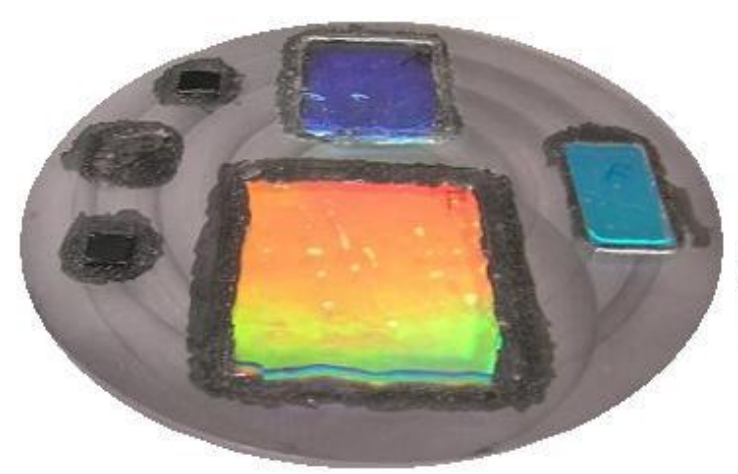

Figure 3-6: Polycarbonate mandrel with attached molds prior to electroforming.

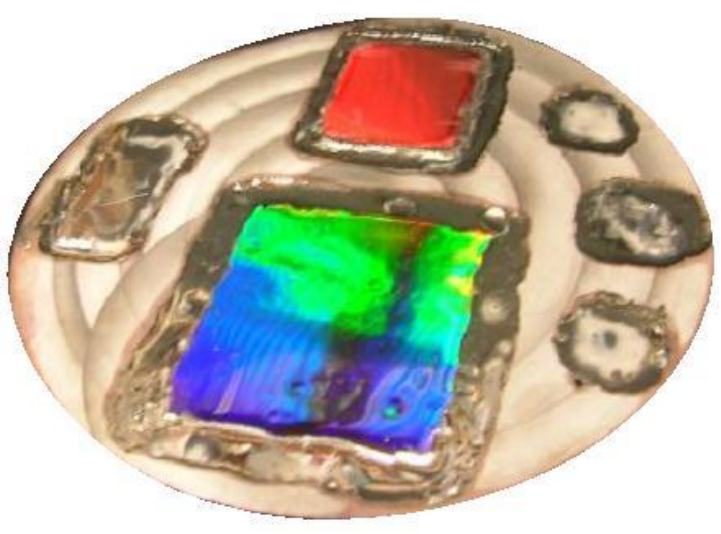

Figure 3-7: Electroform of patterns used in experimentation.

The company that preformed the electroforming of the mandrel was NiCoForm in Rochester, NY. NiCoForm specializes in optical quality electroforms and uses a high strength magnetic nickel-cobalt alloy. A picture of the finished electroform is shown in Figure 3-7. The two largest molds (250nm linewidth, 375nm period, 200nm height in PMMA and 300nm linewidth, 700nm period, 200nm height in ETFE) were replicated with good quality, while the remaining molds were not replicated at all, likely due to poor 
adhesion during the surface metallization process. The electroform is approximately
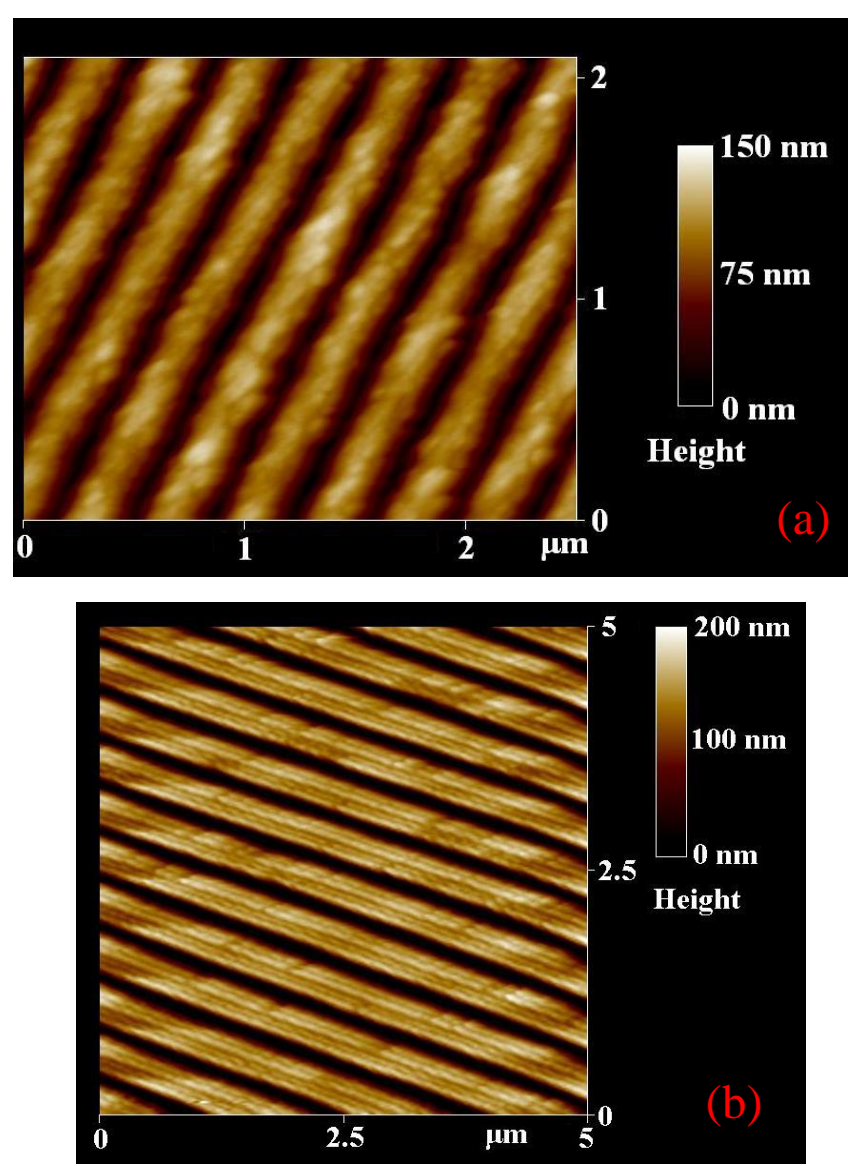

Figure 3-8: AFM images of the electroformed PMMA substrate mold (a) located on the top of the electroform (red tint in Figure 3-7) and of the replicated ETFE substrate mold (b) located on the bottom of the electroform (blue-green tint in

Figure 3-7).
$0.17 \mathrm{~mm}$ in thickness. Atomic force microscopy images of the two well-replicated molds are shown in Figure 3-8. The larger of the two successfully electroformed molds (Figure 38b) was unusable due to excess adhesion between the mold and electroform, causing most of the mold to stick to the electroform. A small $\sim 1 \mathrm{~cm}^{2}$ section of electroformed mold was available for the AFM in Figure 3-8b. 


\section{CHAPTER 4}

\section{EXPERIMENTATION}

\subsection{Preliminary Work}

In preparation for the experimentation phase of this project, preliminary data was taken to determine heating power, roller speed, and roller force. The induction heater was tuned manually using a computer connection to the induction heater through an RS485 cable. The induction heater was forced to try and locate a resonant frequency in a given range of operating frequencies (e.g. force to operate between $100-200 \mathrm{kHz}$ ). For this particular coil design and workpiece, the resonant frequency was found to be 231 $\mathrm{kHz}$. A method to automatically tune the induction heater using the computer interface along with the commands used in this process are included in the Appendix.

One part of the experimental phase of the project will be the acquisition of experimental process parameters for use in simulating embossing R2RNIL. A disadvantage in using induction heating is the large amount of high frequency noise generated in the vicinity of the coil, induction heating supply wires, and the induction heater itself. To avoid this problem entirely, measurements were taken prior to experimentation in isolated mini-experiments. The two major parameter measurements hindered by experimentation are the force measurement between pressure rollers and mold temperature curves. Mold temperature curves must be obtained separate from experimentation, since the pressure between rollers during experimentation would destroy the fragile thermocouples used in the measurement. 


\subsection{Force Measurement}

A dimensionless compression ratio was used to qualitatively measure the pressure at the mold-film interface and was defined as the initial thickness of the mold and film layers divided by the roller spacing. For example, two layers of film $(0.2 \mathrm{~mm} \times 2=$ $0.4 \mathrm{~mm})$ and the mold in between $(0.23 \mathrm{~mm})$ combine to a total thickness of $0.63 \mathrm{~mm}$. A compression ratio of 2 would result from a roller spacing of $0.315 \mathrm{~mm}$ with such a moldfilm thickness. Feeler gauges were used to set the mold spacing to assign a desired compression ratio. The correlation between these two parameters is dependent on the material used and the temperature of the materials, therefore these variables should remain constant between the correlation experiments and actual experiments for a completely accurate comparison. A compression ratio corresponding to a desired applied force can be set by physically adjusting roller spacing using feeler gauges.

The displacement screws on the Stanat machine used to set roller spacing allow for space to insert spacers with attached strain gauges. A pair of solid aluminum discs approximately $19 \mathrm{~mm}$ in diameter was precisely machined, and a pair of strain gauges was glued to each side of each disc (a total of four strain gauges). Such large diameter discs serve a twofold purpose: they provide the stiffness required in maintaining the zerodeflection assumption in the roller spacing, and they must withstand the large force applied during operation. These discs were then connected to a strain gauge bridge and calibrated on an Instron testing machine, which provided strain-force curves to correlate measured strain to applied force. The discs were then tightly fit in-between the displacement screw and brass roller bearing, as shown in Figure 4-1. In the test experiment for this setup a single PET film layer, mold, and two strips of heat-resistant 
adhesive tape were preheated to $110^{\circ} \mathrm{C}$ and fed through the pressure rollers at a compression ratio of 1.5 . The strain gauges revealed a force of $\sim 3000 \mathrm{~N}$; therefore a compression ratio of 1.5 with this 'sandwich' layering at this temperature corresponds to a force of $3 \mathrm{kN}$. This is a reasonable force considering the film-mold section is being stressed to $50 \%$ compressive strain very quickly.

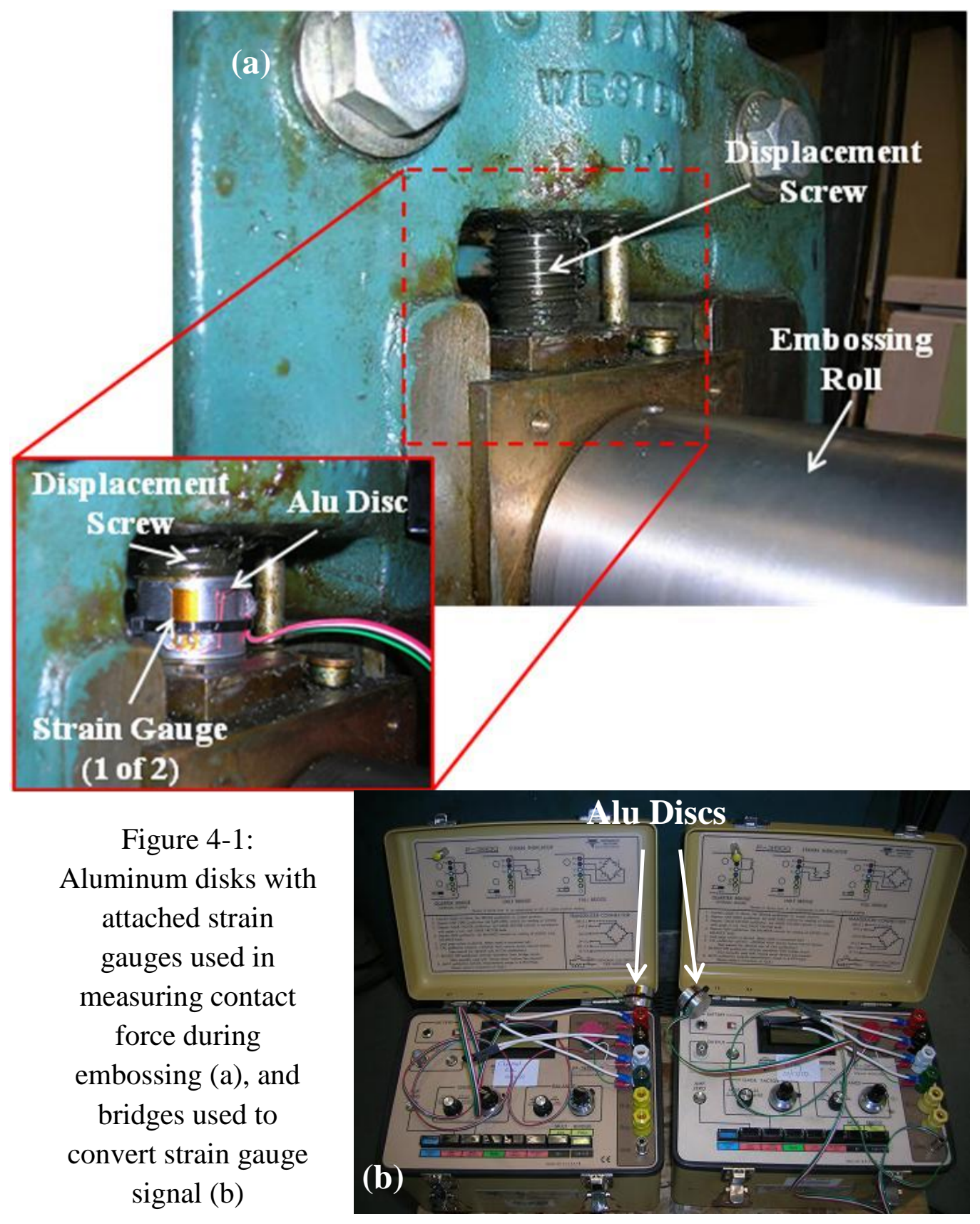




\subsection{Mold Surface Temperature Measurement}

Mold surface temperature measurements were acquired by fixing a thermocouple to the surface of the conveyor mold using heat-resistant tape. The Stanat machine was then activated and the mold was allowed to move through the activated induction heating coil just as it would in an actual experiment. A set of heating curves for various induction heating power levels (\% maximum) and roller speeds (\% maximum in $1^{\text {st }}$ gear) is

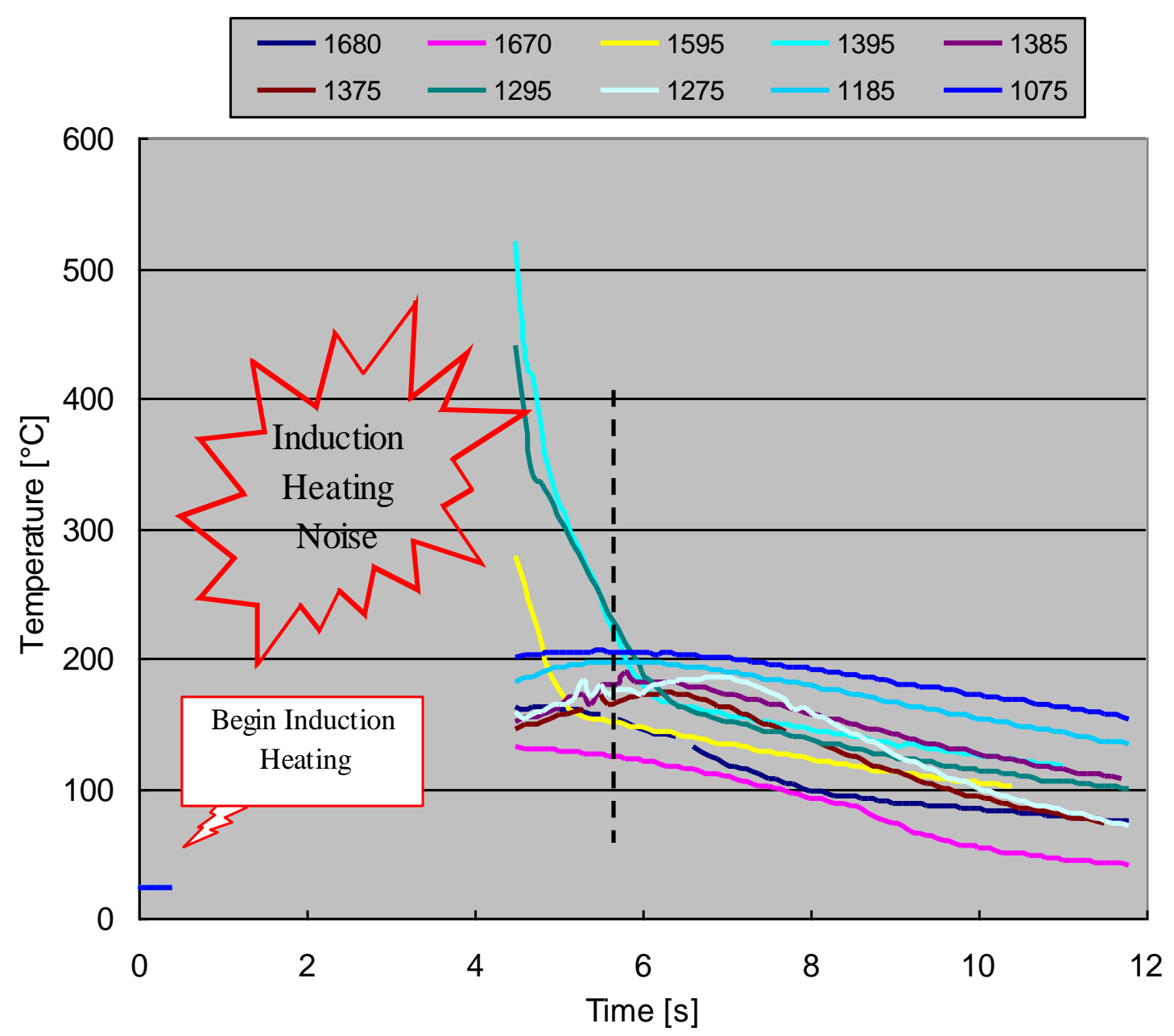

Figure 4-2: Mold surface temperature versus time after induction heating for the $30 \mu \mathrm{m}$ nickel mold. First two digits of legend indicate speed of mold (\% maximum roller speed in $1^{\text {st }}$ gear) and last two digits indicate induction heating power (\% maximum). 
included in Figure 4-2. This graph plots mold surface temperature versus time for the $30 \mu \mathrm{m}$ mold, with the actual heating curve omitted due to noise from the induction heating coil (high intensity electromagnetic field generation) interacting with the thermocouple signal. The mold begins heating from $20^{\circ} \mathrm{C}$ and the mold moves through the coil at various speeds (first two digits of scale, \% maximum roller speed) and varying induction heating power (last two digits of scale, \% maximum). The linear mold velocity is proportional to the roller rotational speed, and a roller rotational speed of $12.5 \%$ maximum corresponds to $6.58 \mathrm{rpm}$, or a linear mold velocity of $26 \mathrm{~mm}-\mathrm{s}^{-1}$. The effect of slower roller speed is a longer heating time, generally resulting in higher mold surface temperatures after exiting the induction heating coil, and this is an expected result. The dashed line is an approximation of the temperature at which the mold contacts the film, and does vary slightly depending on roller/film speed.

Analyzing the curves of constant speed and varying induction heating power reveal a much more interesting result. For induction heating powers below $95 \%$ maximum, the peak mold surface temperatures approach $200^{\circ} \mathrm{C}$ for even the slowest speed of $10 \%$ maximum roller speed; while using roller speeds lower than this value occasional stalling was found to occur, therefore this was the lowest speed tested. For an induction heating power of $95 \%$, a completely different cooling slope and much higher peak temperatures are observed initially, until finally joining the same slope and temperatures as the tests at lower power. An explanation for this large jump in mold surface temperature when reaching a specific induction heating power would be that at such a 'threshold' induction heating power, the heating rate at the surface of the mold due to the induction heating becomes much faster than the conduction of heat to the core of the mold. This would 


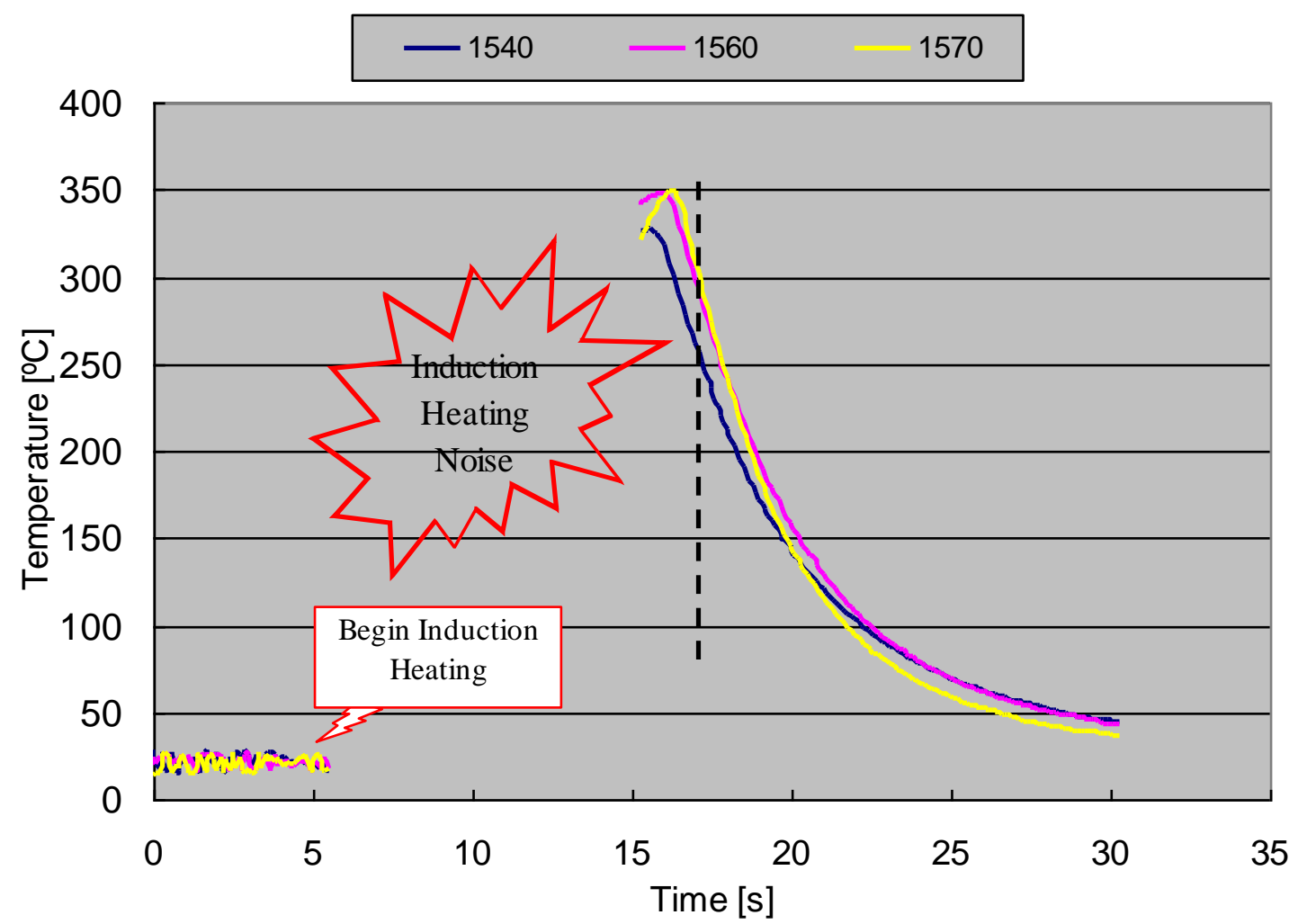

Figure 4-3: Induction heating-temperature response for electroformed Nickel-Cobalt alloy. The legend used here is the same format as that of Figure 4-2.

result in a much higher surface temperature, and a faster cooling rate as the temperature of the core did not change during heating, but quickly absorbs heat once the conduction of heat from the surface of the mold becomes greater than that supplied by induction heating.

The electroform molds, being composed of a different alloy ( $98 \% \mathrm{Ni}, \sim 2 \% \mathrm{Co})$ than the $30 \mu \mathrm{m}$ mold $(\sim 100 \% \mathrm{Ni})$, had much different induction heating-temperature response curves. The results for three different heating percentages at a roller speed of $15 \%$ maximum is shown in Figure 4-3. The induction heating efficiency was observed to be 
much better with this specific alloy, and lower induction heating power was needed to achieve the same temperature response as compared with the nickel $30 \mu \mathrm{m}$ mold.

\subsection{Finalized R2R System}

A front view of the R2R system used in experimentation is included in Figure 4-4. Figure 4-4(a) shows the panoramic view of the entire system; beginning from the left side of the picture is the computer interface used to control the induction heater. The UV light control sits between the computer interface and the Stanat machine, and the induction heater is the rightmost instrument in Figure 4-4(a). The cartoon diagram shown previously in Figure 3-2 is a cross-sectional view of the actual setup shown in Figure 44(b). 


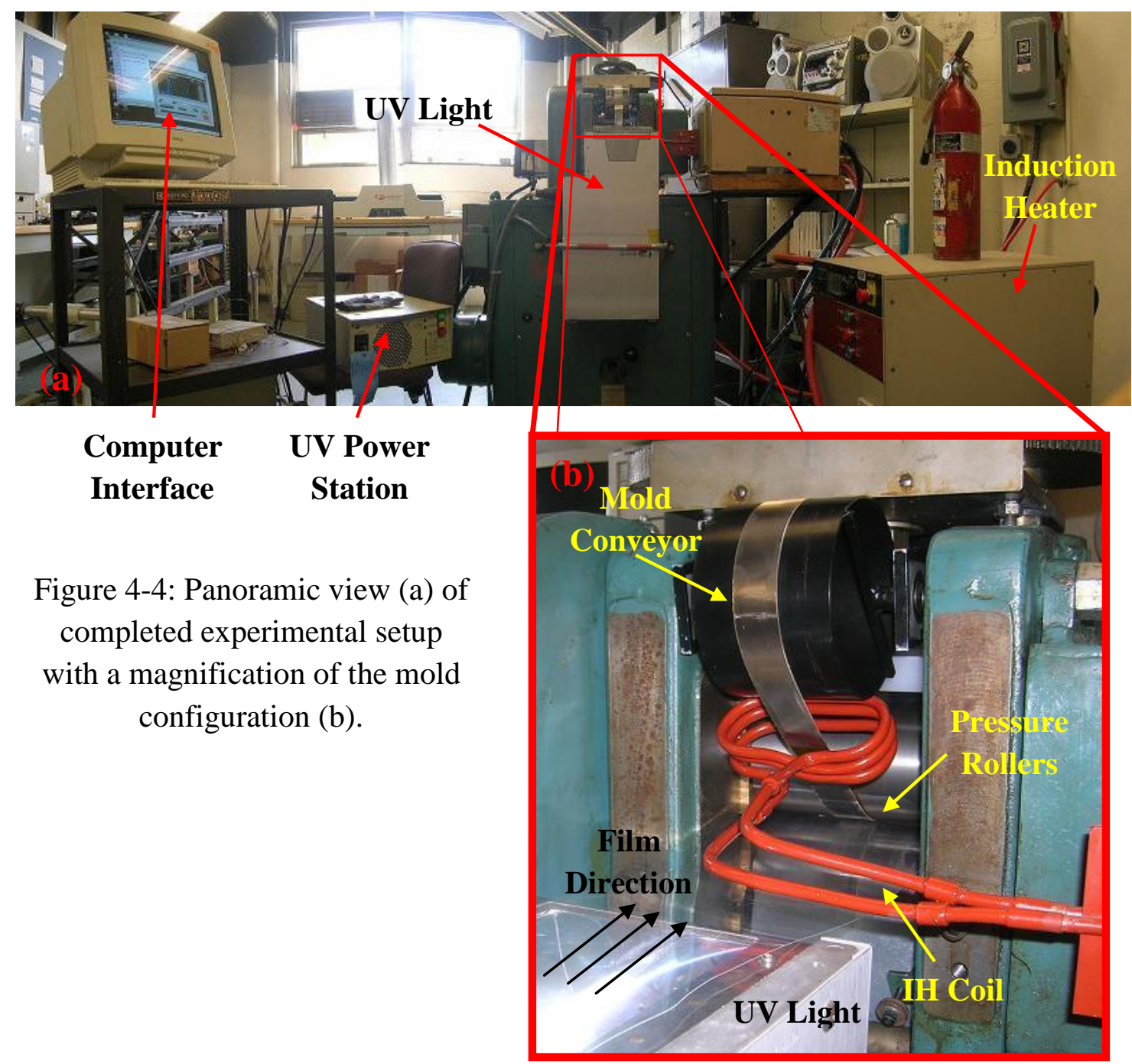

Due to the geometrical constraints of the mold conveyor path, the embossing roller was within the induction heating proximity of the induction heating coil. As a consequence of this, the magnetic steel embossing roll was heated along with the nickel mold; however, this effect should be small due to the large distance from the coil (< $25 \mathrm{~mm}$ ) and the high thermal inertia of the embossing roller. 


\subsection{Film Speed}

In order to determine a proper film speed, a brief investigation into the time required for the polymer to flow into the mold features should be preformed. The mold flow during embossing can be adequately described as 1-dimensional flow between a pair of

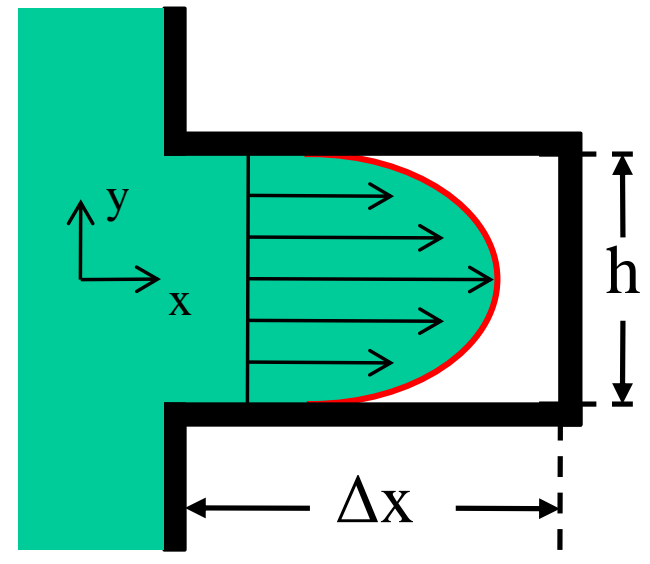

Figure 4-5: Model used to represent flow into a micro-/nanofeature.

infinitely long plates, as shown in Figure 4-5. The primary driving force moving the polymer into the features is the pressure difference created by the embossing rollers during molding. Using the basic equation for 1-D, pressure-driven, flow between two infinitely long plates the derivation begins as follows:

$$
\frac{\partial P}{\partial x}=-\eta \frac{\partial^{2} u_{x}}{\partial y^{2}}
$$

where $\partial p / \partial x$ is the pressure gradient, $\eta$ is the viscosity, and $u_{x}$ is the flow velocity in the x-direction. Solving for ux with a "no-slip" boundary condition at the walls,

$$
u_{x}=-\frac{\partial P}{\partial x} \frac{1}{2 \eta}\left(\frac{h^{2}}{4}-y^{2}\right)
$$

which details the profile of the $\mathrm{x}$-directional flow front as a function of distance from the neutral flow axis. In order to properly characterize the fill time, we need to find the average velocity of the flow front: 


$$
\bar{u}_{x}=\frac{1}{h} \int_{-h / 2}^{h / 2} u_{x} d y=-\frac{\Delta P}{\Delta x} \frac{h^{2}}{12 \eta}
$$

The fill time can now be calculated as follows:

$$
t_{\text {fill }}=\frac{\Delta x}{\bar{u}_{x}}=-\frac{12 \eta}{\Delta P}\left(\frac{\Delta x}{h}\right)^{2}
$$

One notable feature about this relation for fill time is the fact that so long as $\Delta \mathrm{x}$ and $\mathrm{h}$ scale equally (constant aspect ratio), the fill time remains constant. $[49,50]$

To begin solving for numerical values of the fill time, the viscosity and pressure difference must be determined. A good approximation for polymer viscosity for temperatures near the glass transition is the Williams-Landel-Ferry (WLF) equation, shown below

$$
\eta(T)=\eta_{0} \exp \left[\frac{-C_{1}\left(T-T_{g}\right)}{C_{2}+T-T_{g}}\right]
$$

where $\eta(T)$ is the temperature-dependant viscosity, $\eta_{0}$ is the viscosity at the glass transition temperature, $\mathrm{C}_{1} \approx 17.4, \mathrm{C}_{2} \approx 51.6[\mathrm{~K}]$, and $\mathrm{T}_{\mathrm{g}}$ is the glass transition temperature. The constants $\mathrm{C}_{1}$ and $\mathrm{C}_{2}$ are generally material-dependant but the given values are considered to be approximate for the entire range of glassy polymers, and for the purpose of a quick approximation of the viscosity these values will suffice. Using an experimental value for the viscosity of PET near its melt temperature $(\eta=4000 \mathrm{P} @ \mathrm{~T}=$ $\left.280^{\circ} \mathrm{C}\right), \eta_{0}$ is calculated to be $4.06 \mathrm{e} 9$ Poise. Plotting T vs. $\log (\eta)$ for values beginning at the glass transition temperature and past the melting point of PET, the curve shown in 
Figure 4-6 is generated. The minimum temperature for embossing will be the $120^{\circ} \mathrm{C}(\mathrm{Tg}$ $+40^{\circ} \mathrm{C}$ ) and the maximum temperature will be $250^{\circ} \mathrm{C}$ since this value is the maximum rated temperature of the adhesive holding together the conveyor mold. Values of the viscosity at $120^{\circ} \mathrm{C}$ and $250^{\circ} \mathrm{C}$ are $2.03 \mathrm{e} 6 \mathrm{P}$ and $6.84 \mathrm{e} 3 \mathrm{P}$, respectively. [33]

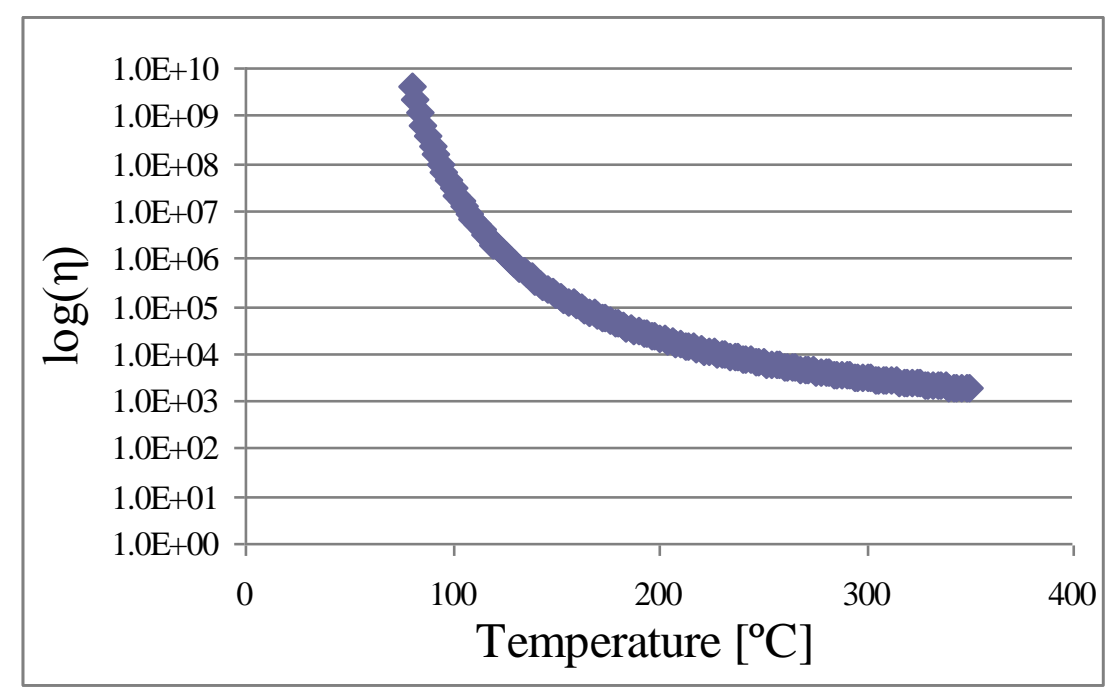

Figure 4-6: Semi-log plot of temperature-viscosity relationship of PET according to the WLF equation using generalized polymer constants.

To determine the pressure needed for the calculation of fill time, the contact area of the film is needed. The width of the mold, for the $30 \mu \mathrm{m}$ features, is $25 \mathrm{~mm}$ and the contact force was previously measured to be $3000 \mathrm{~N}$. A measurement for contact force was only taken using the $30 \mu \mathrm{m}$ mold, therefore for this fill approximation it will be assumed that the calculated pressure for this mold will be identical to the pressure using the remainder of the molds. The contact length of the embossing stage can be calculated on a purely geometrical basis, as shown in Figure 4-7 for a contact ratio of $1.5(0.56 \mathrm{~mm} /$ $1.5=0.38 \mathrm{~mm}$ ). Using Pythagoreans theorem the value of $\mathrm{L}_{\text {contact }}$ can be calculated to be $5.1 \mathrm{~mm}$. The average pressure over this contact area can now be calculated using the 
$3000 \mathrm{~N}$ contact force and the mold width and contact length through the following formula

$$
\Delta P=\frac{F}{A}=\frac{F}{w_{\text {mold }} L_{\text {contact }}}=24 M P a
$$

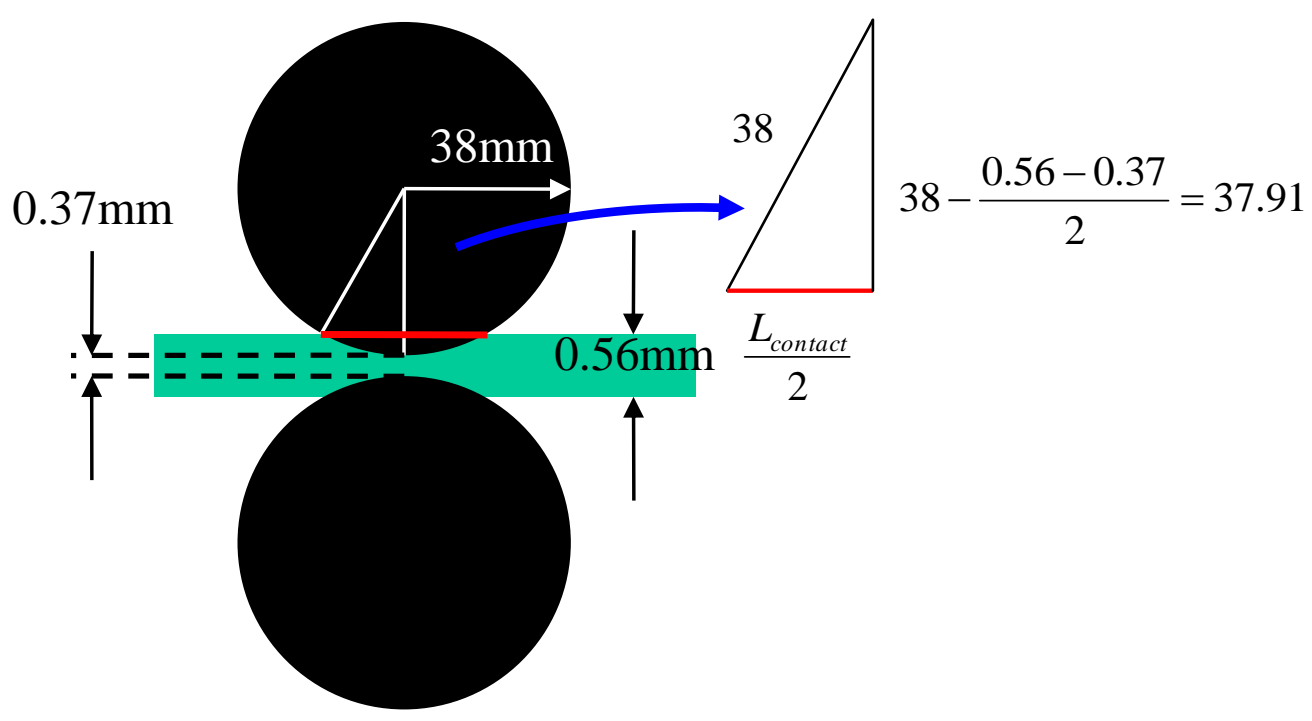

Figure 4-7: Geometrical representation of embossing stage.

Inserting values for pressure and viscosity, and using an aspect ratio of $1(\Delta x=h)$, numerical values for the fill time can be determined for the boundary temperatures. For a temperature of $120^{\circ} \mathrm{C}$ a fill time of $1.015 \mathrm{~s}$ is calculated, and for a temperature of $250^{\circ} \mathrm{C} \mathrm{a}$ fill time of $0.003 \mathrm{~s}$ is calculated. This three order of magnitude difference in fill time is attributed to the same difference in viscosities at these two temperatures, since fill time is proportional to viscosity. To determine the maximum limit on film speed can be determined through the following relationship: 


$$
\text { FilmSpeed }=\frac{L_{\text {contact }}}{t_{\text {contact }}}
$$

where $t_{\text {contact }}$ is the length of time the mold and film are compressed between embossing rolls (embossing time). Using the fill time as the minimum contact time required for proper filling of the features, we can obtain the maximum film speed satisfying this requirement. At a temperature of $120^{\circ} \mathrm{C}$ with a fill time of $1.015 \mathrm{~s}$ a maximum film speed of $5.1 \mathrm{~mm}-\mathrm{s}^{-1}$ is calculated, and at a temperature of $250^{\circ} \mathrm{C}$ with a fill time of $0.003 \mathrm{~s}$ a maximum film speed of $1693 \mathrm{~mm}^{-\mathrm{s}^{-1}}$ is calculated. Due to limitations on roller speed, the minimum roller speed that can be reliably achieved without stalling the roll press is $10 \%$ of maximum roller speed in $1^{\text {st }}$ gear, or $21 \mathrm{~mm}-\mathrm{s}^{-1}$, therefore complete filling is not expected to occur at temperatures of $120^{\circ} \mathrm{C}$. In taking a different approach of solving for the aspect ratio $(\Delta \mathrm{x} / \mathrm{h})$ in Equation 4.4 by setting the fill time from Equation 4.4 equal to the contact time for a known film speed in Equation 4.7, the maximum feature aspect ratio that can be replicated may be determined. For a film speed of $25 \mathrm{~mm}-\mathrm{s}^{-1}$ at a film temperature of $250^{\circ} \mathrm{C}$, an aspect ratio of $\sim 8$ could be achieved on the basis of the preceding analysis.

\subsection{R2R Experimental Procedure}

To achieve the required film pre-heating temperature at embossing, the gap length of UV heating was determined. With a known heating rate of the UV light in the PET film (the slope of the red heating curve in Figure 2-4) and a known linear film speed, gap length of UV light could be calculated for target preheat temperatures. 


$$
L_{U V}=\left(t_{U V}\right)(\text { FilmSpeed })=\left(\frac{T_{\text {preheat }}}{\text { HeatRate }}\right)(\text { FilmSpeed })
$$

To block the remaining length of the $125 \mathrm{~mm}$ UV light shutter, a UV absorbent Pyrex plate was fixed over the surface of the UV light, leaving only the calculated gap to allow the UV light to heat the passing film during experimentation.

For molding with the nickel $30 \mu \mathrm{m}$ mold the procedure is as follows. The total moldfilm thickness was measured to be $0.56 \mathrm{~mm}$, and included the mold, film, and two layers of high-temperature tape. For a compression ratio of 1.5 , a roller gap of $0.37 \mathrm{~mm}$ is required. The gap spacing was set during experimentation since closing the gap on a cold mold and glassy film would destroy the mold. A $600 \mathrm{~mm}$ long section of $152 \mathrm{~mm}$ wide PET film, $0.20 \mathrm{~mm}$ thickness, was cut into a $102 \mathrm{~mm}$ wide section. The film was then fed over the UV light, through the R2R embossing rollers, over the lift-off roller and out the backside of the machine. With the PET film already inserted in the R2R machine, the experiment began by first turning on the 80psi cooling air. The motor drive on the Stanat machine was than activated, and the UV light and induction heater were activated once the film began moving. A lab assistant supplied film tension at the back of the machine manually.

Experiments were performed for varying roller speeds, induction heating power, and compression ratio. Pre-heating temperature was kept about $200^{\circ} \mathrm{C}$ to maximize the viscous properties of the film but not allow gross film deformation by excess heat, since the melting temperature of PET is $250^{\circ} \mathrm{C}$. Since roller speed and induction heating power were both correlated with mold surface temperature, as shown previously in Figure 4-2 
and Figure 4-3, target values for mold surface temperature were chosen as experimental variables.

After allowing 2-3 seconds for the R2RNIL embossing system to warm up, the roller gap was closed to $0.37 \mathrm{~mm}$ and embossing began. For experiments performed with a target mold temperature under $200^{\circ} \mathrm{C}$, embossing was continued until the end of the film was reached after around 25 seconds of elapsed experiment time. After accounting for time between activating the instruments and warm-up, about 15 seconds of embossing occurred corresponding to approximately 500 linear millimeters of embossed film, which varied depending on the roller/film speed used in the particular experiment. For experiments with a target mold temperature greater than $200^{\circ} \mathrm{C}$, embossing was preformed only on single mold ribbons, since heating the ribbon connection higher than $200^{\circ} \mathrm{C}$ was observed to cause adhesive failure under mold conveyor tension. Embossing in this way could only create patterned films $125-150 \mathrm{~mm}$ in length using the $30 \mu \mathrm{m}$ mold. [32]

For experimentation using the electroformed $250 \mathrm{~nm}$ linewidth $375 \mathrm{~nm}$ period mold, the conveyor mold setup was changed due to the small area of electroform to be patterned. The majority of the conveyor was composed of a single PET film strip connected by a layer of heat resistant tape. The electroformed mold was placed on this layer of heat resistant tape and secured using another layer of tape. Figure 4-8 shows the mold conveyor for the electroformed molds. The mold layering consisted of two layers of heat resistant tape, the mold, and the substrate film for a total thickness of $0.47 \mathrm{~mm}$. For a CR of 1.5 to be achieved a roller spacing of $0.31 \mathrm{~mm}$ was required. Based on the 
results from the replication of the $30 \mu \mathrm{m}$ mold features, a mold surface temperature of $250^{\circ} \mathrm{C}$ was targeted for experimentation using this mold.

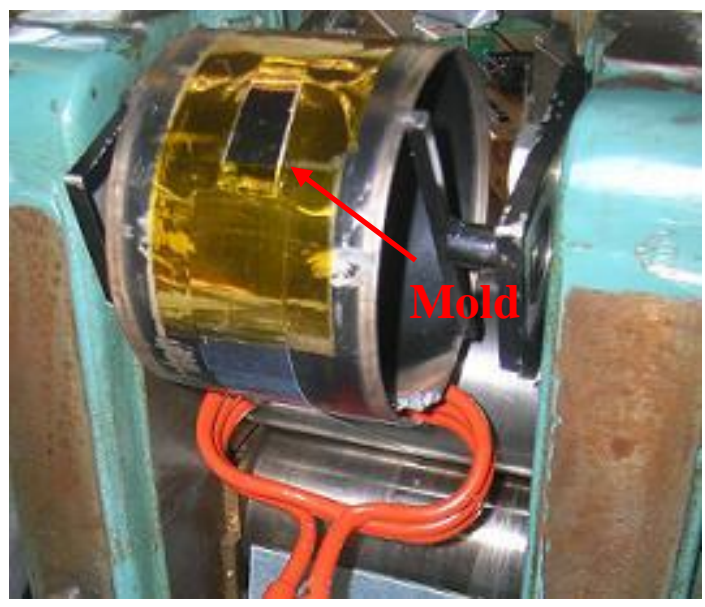

Figure 4-8: Mold conveyor using a section of electroformed mold. 


\section{CHAPTER 5}

\section{RESULTS AND CONCLUSION}

\subsection{Pattern Characterization}

During experimentation using constant mold surface temperature and varying compression ratio, it was determined that a CR of 1.5 was ideal. CR values higher than 1.75 leaded to film deformation that overwhelmed the replicated pattern; such types of deformation were visible as sharkskin and wavy surface profiles. CR values higher than 2.00 actually deformed the nickel mold used in experimentation. For CR values below 1.30, patterns on the surface of the substrate were not visible to the naked eye and laser light revealed weak to no diffraction pattern, which are apparent in the $30 \mu \mathrm{m}$ pattern.

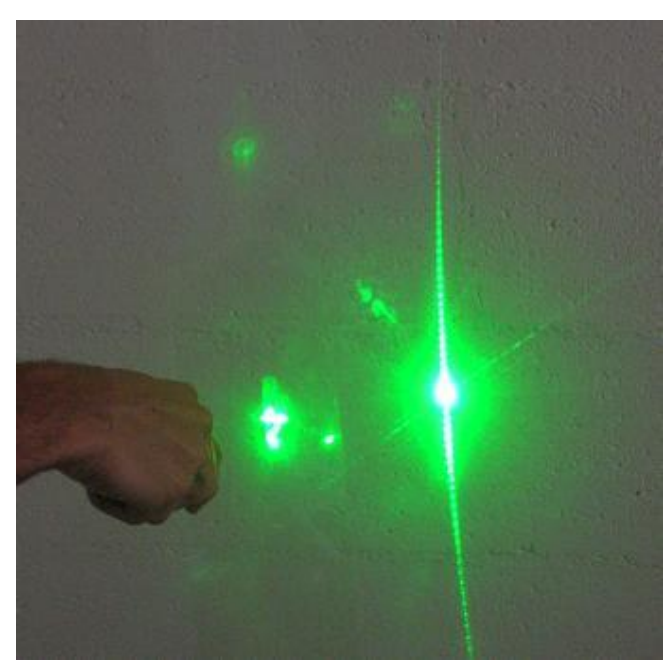

Figure 5-1: Diffraction pattern of replicated $30 \mu \mathrm{m}$ sawtooth pattern. heating power and roller speed were backed out of the induction heating-temperature mold response curve of Figure 4-2 and used in experimentation. The patterns were characterized using both profilometry and scanning electron microscopy. Figure 5-2 shows profilometry and SEM results for patterns mold upon exposure to green laser light is shown in Figure 5-1.

For the $30 \mu \mathrm{m}$ nickel mold, a range of mold surface temperatures from $130^{\circ} \mathrm{C}$ to $250^{\circ} \mathrm{C}$ was used for a constant CR of 1.5 and a film preheat temperature of $200^{\circ} \mathrm{C}$. From the target mold surface temperature, a proper induction

The diffraction pattern for one such replicated 
replicated using the $30 \mu \mathrm{m}$ mold at $130^{\circ} \mathrm{C}$ (a) and $250^{\circ} \mathrm{C}$ (b) as well as for the mold itself (c). The profilometer results for the mold only show the features approximately $8 \mu \mathrm{m}$ in height; this is probably a result of the profilometer tip being unable to completely probe the surface of the mold due to the shape and size of the tip, the round tip cannot properly reveal the surface characteristics of the sharp sawtooth troughs. The SEM image ( 900x) of the $30 \mu \mathrm{m}$ mold shows only light pressing marks present on the surface of the PET film; the scale bar in the lower left corner of the SEM image is $30 \mu \mathrm{m}$ in length. A microtomed cross-section of the film did not reveal the presence of microfeatures, possibly because the microtoming process disturbed the features. The profilometry results for the $130^{\circ} \mathrm{C}$ patterned film show wavy features slightly over one micron in height. Figure 5-2(b) shows the results for the patterns replicated at a mold surface temperature of $250^{\circ} \mathrm{C}$, the melt temperature of PET. Although the height of the patterns is not clear from the SEM image, the shape of the patterns is certainly more defined. The profilometer results confirm this, showing a more distinct sawtooth shape almost four microns in height. The features were transferred at a linear film rate of $25 \mathrm{~mm}-\mathrm{s}^{-1}$. 


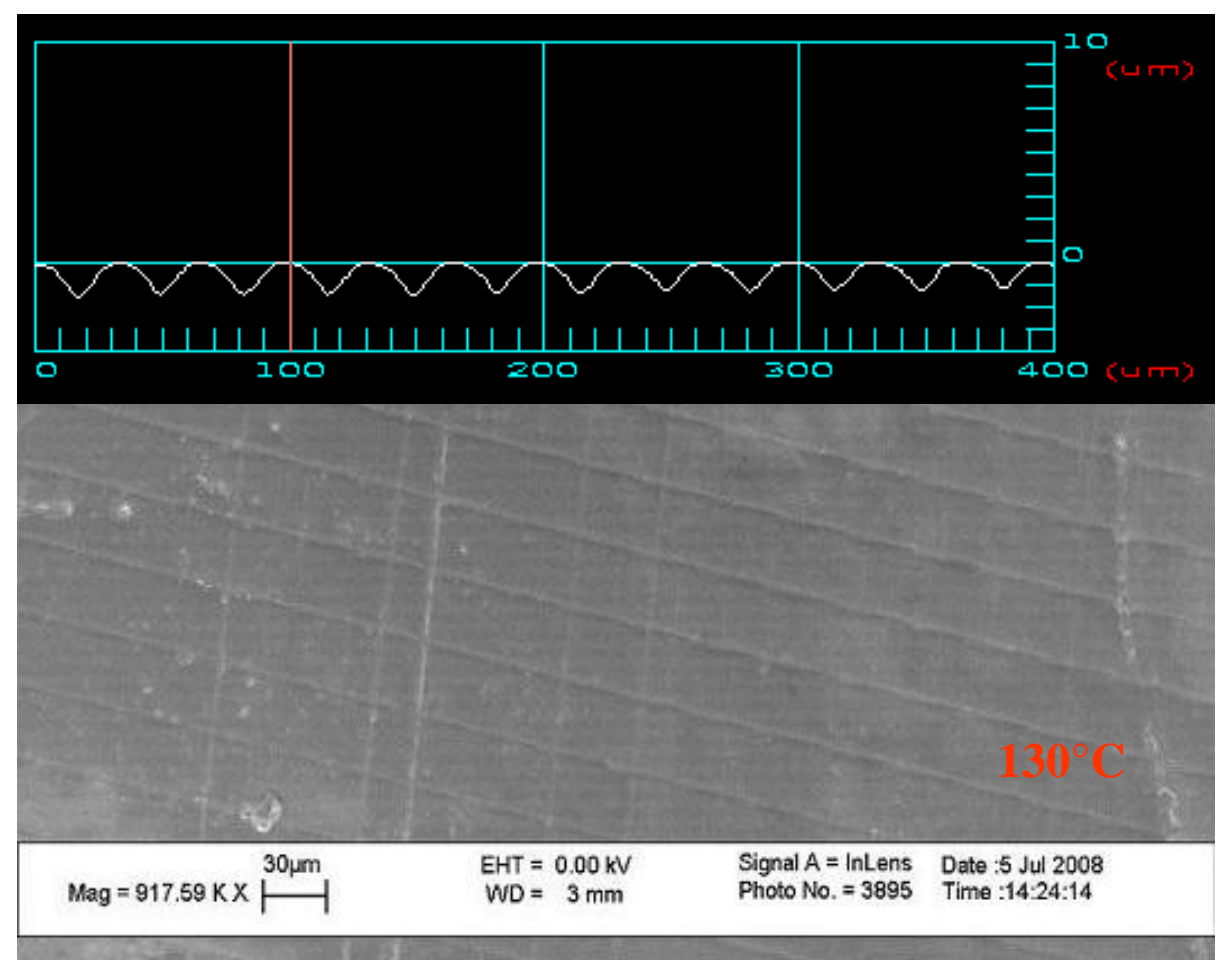

Figure 5-2(a): SEM and profilometry results for replicated $30 \mu \mathrm{m}$ patterns at $130^{\circ} \mathrm{C}$.

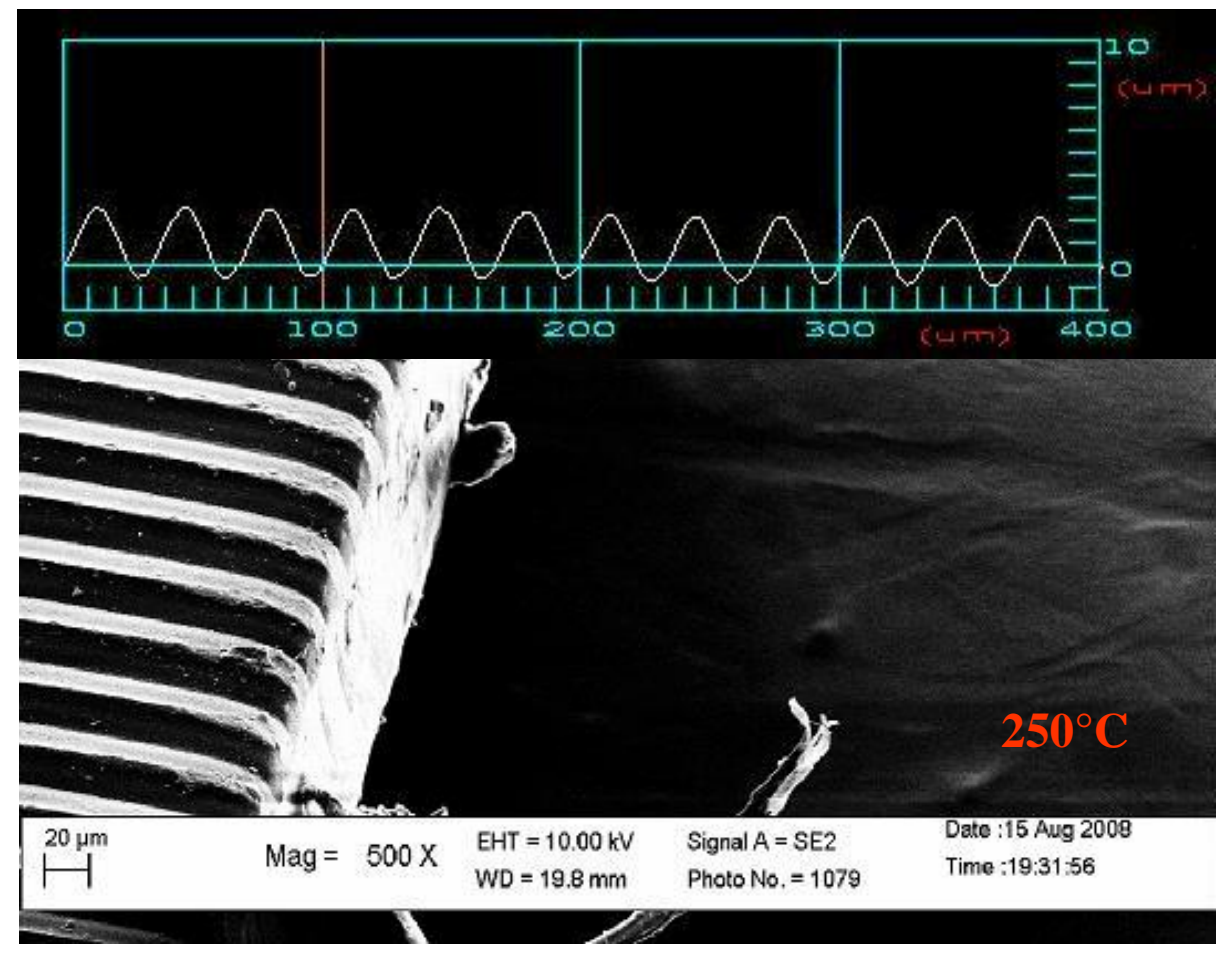

Figure 5-2(b): SEM and profilometry results for replicated $30 \mu \mathrm{m}$ patterns at $250^{\circ} \mathrm{C}$. 


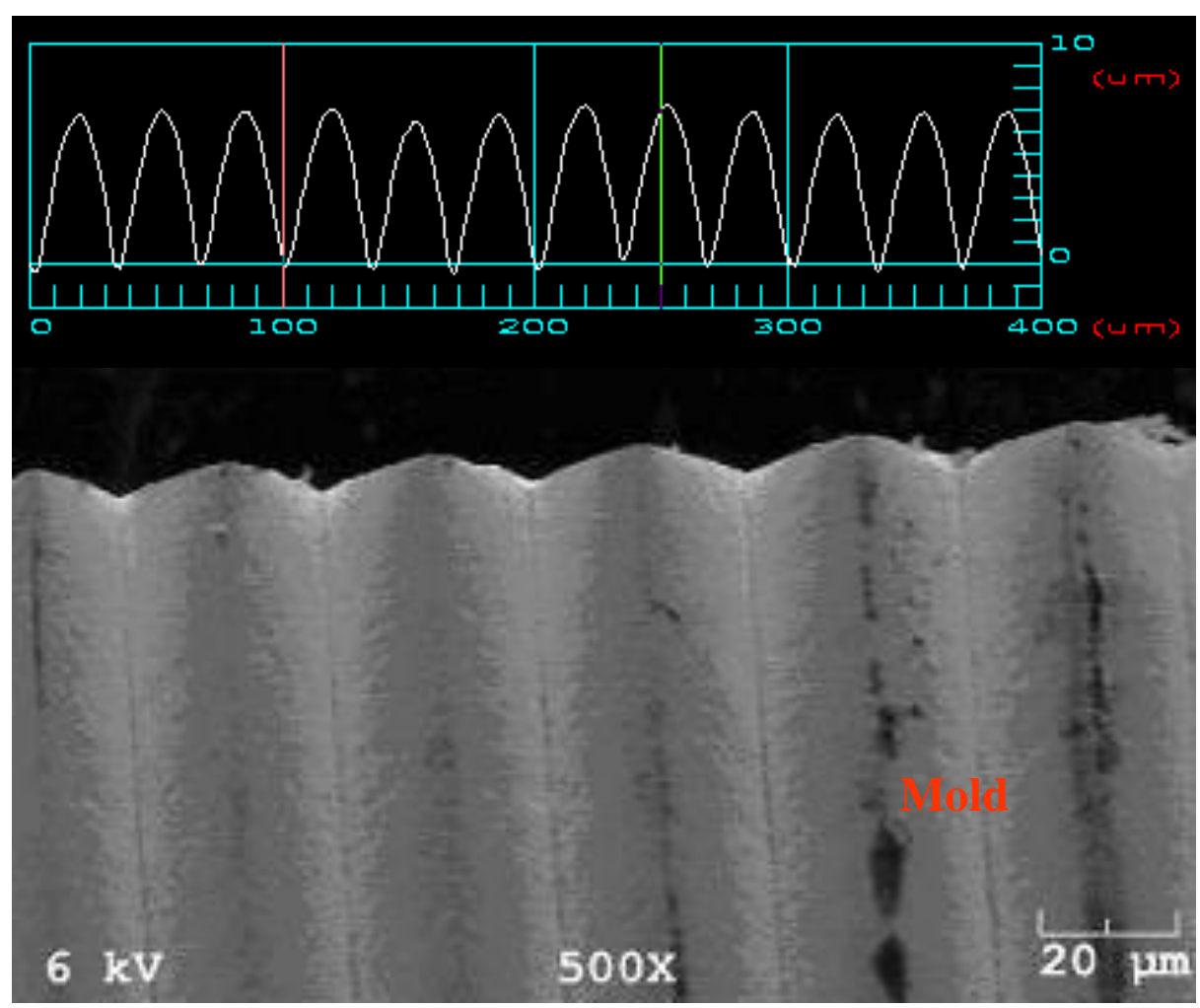

Figure 5-2(c): SEM and profilometry results of the original mold.

The replication of the electroformed $250 \mathrm{~nm}$ linewidth $375 \mathrm{~nm}$ period pattern was accomplished using mold surface temperatures of $250^{\circ} \mathrm{C}$ at a speed of $31 \mathrm{~mm}-\mathrm{s}^{-1}$, but no patterns were observed for mold surface temperatures of $200^{\circ} \mathrm{C}$. The pattern is approximately $150 \mathrm{~mm}$ in length. Atomic force microscopy results show that the pattern did successfully transfer to the PET film, however, the quality of the replication needs to be improved. AFM results for the replicated film along with the original mold before electroforming are shown in Figure 5-3. These features were transferred at a linear film speed of $31 \mathrm{~mm}-\mathrm{s}^{-1}$. 


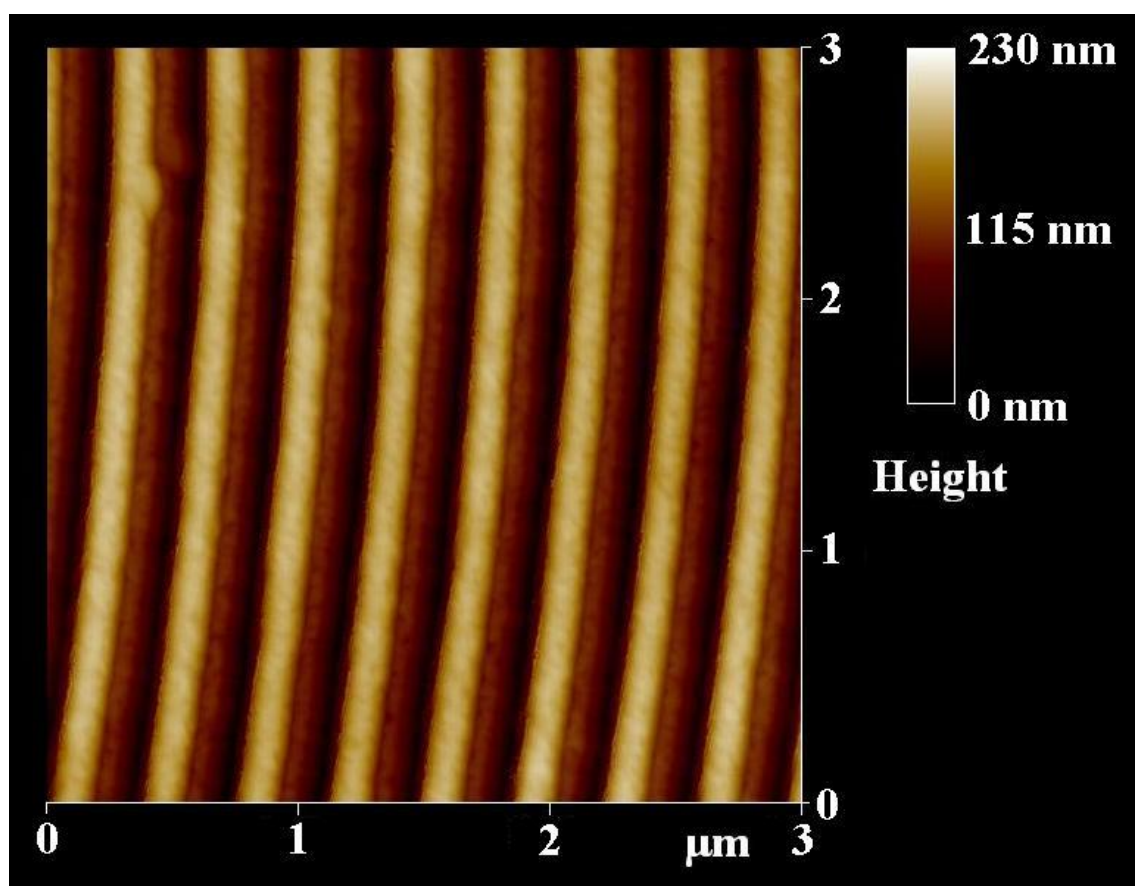

Figure 5-3(a): Top-down AFM view of the original mold in PMMA with 250nm linewidth, $375 \mathrm{~nm}$ period, and 200nm height.

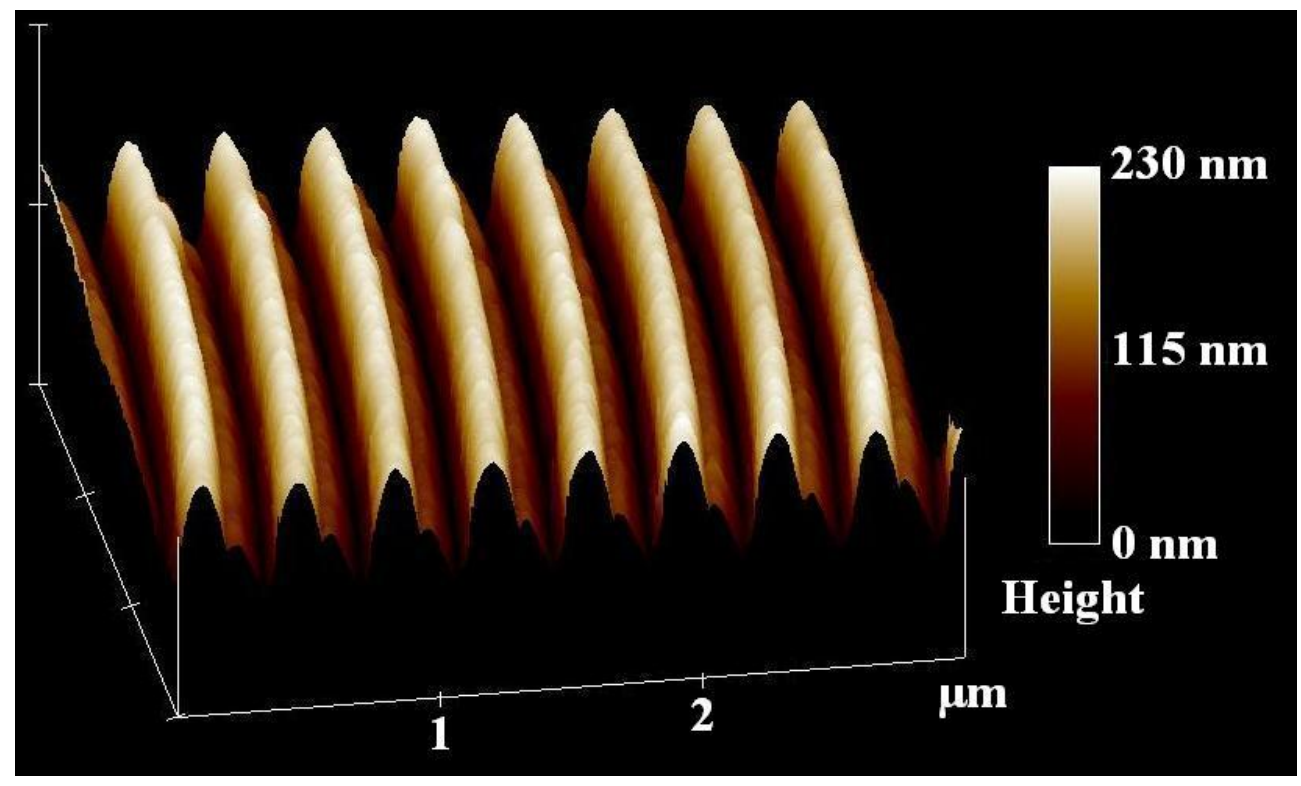

Figure 5-3(b): Tilted AFM section view of the original mold in PMMA with $250 \mathrm{~nm}$ linewidth, $375 \mathrm{~nm}$ period, and $200 \mathrm{~nm}$ height. 


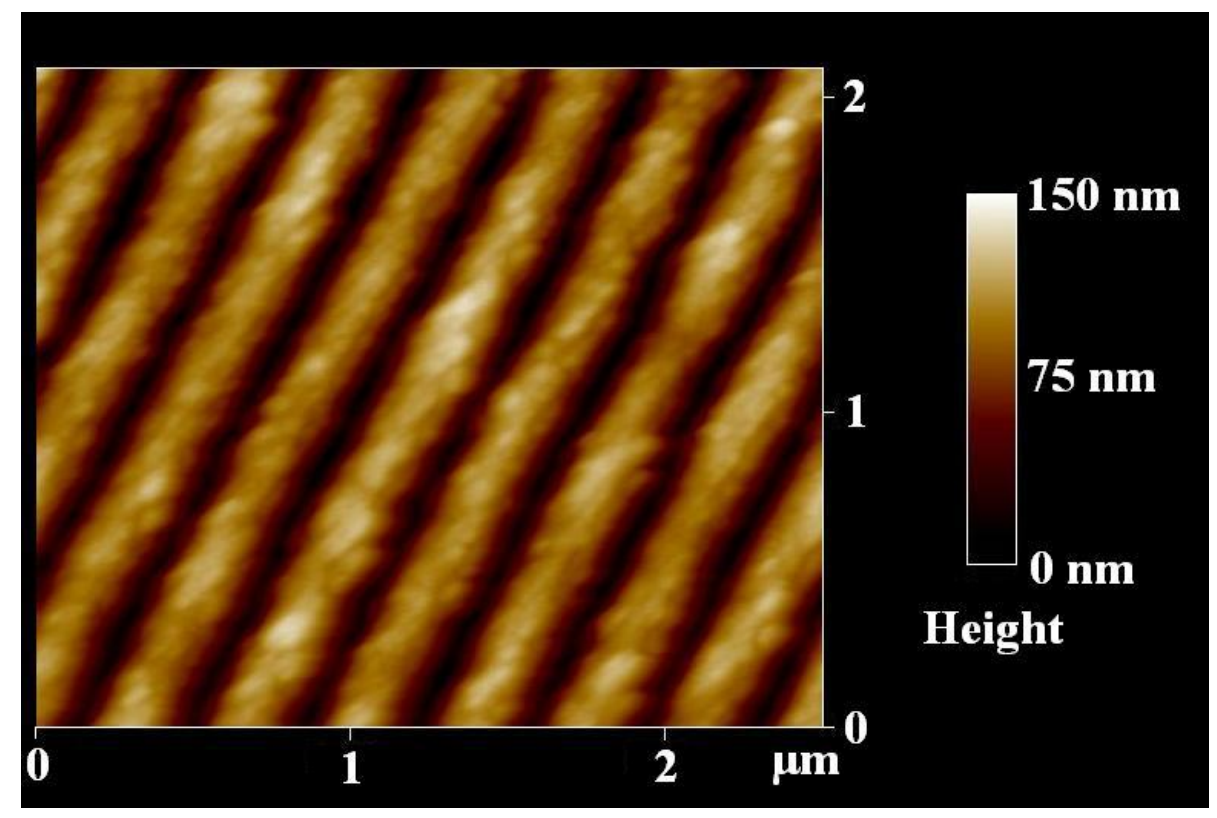

Figure 5-3(c): Top down AFM view of the electroformed copy of the PMMA mold.

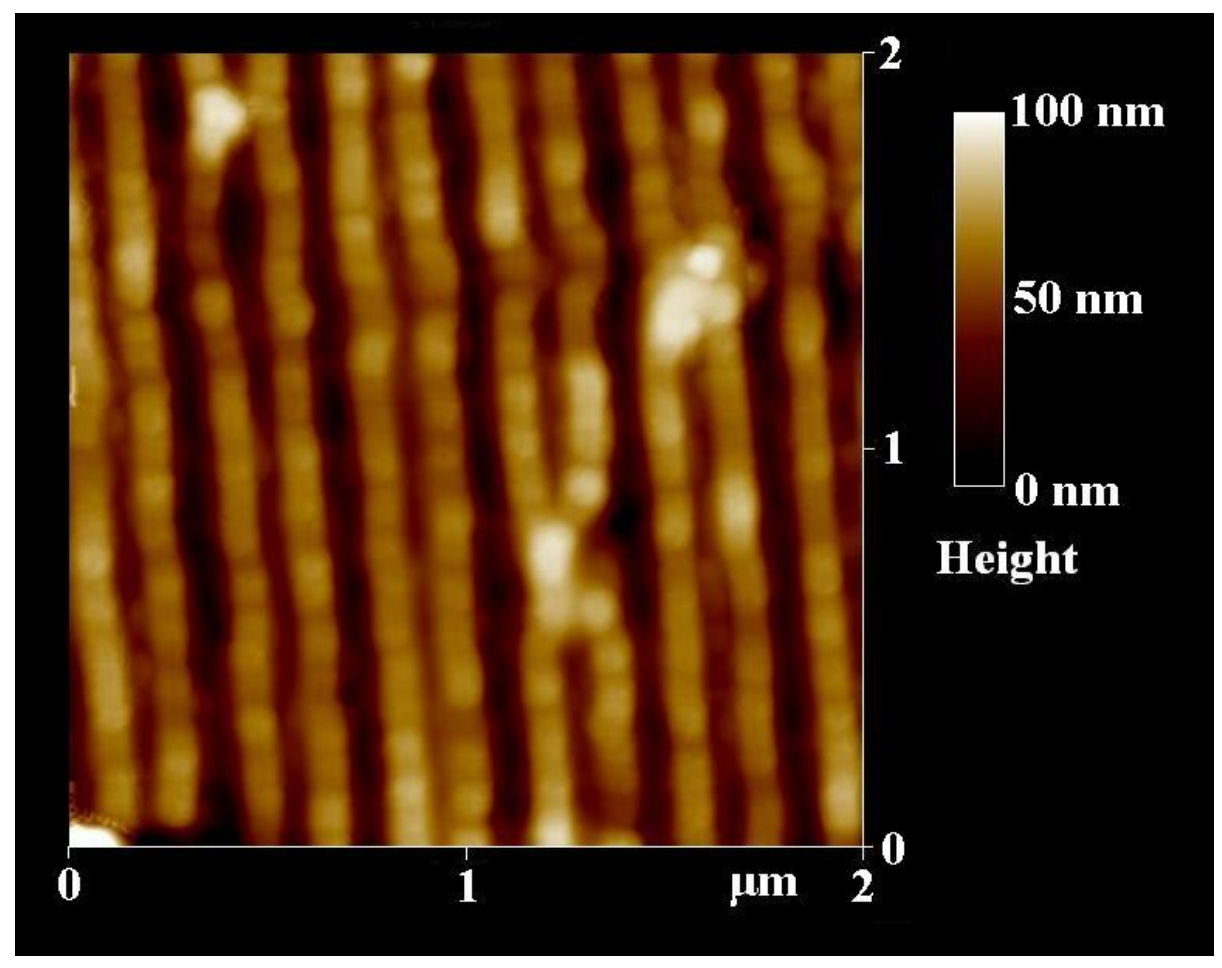

Figure 5-3(d): Top down AFM view after performing R2RNIL on PET using the electroform of the mold, revealing the presence of the structure. 


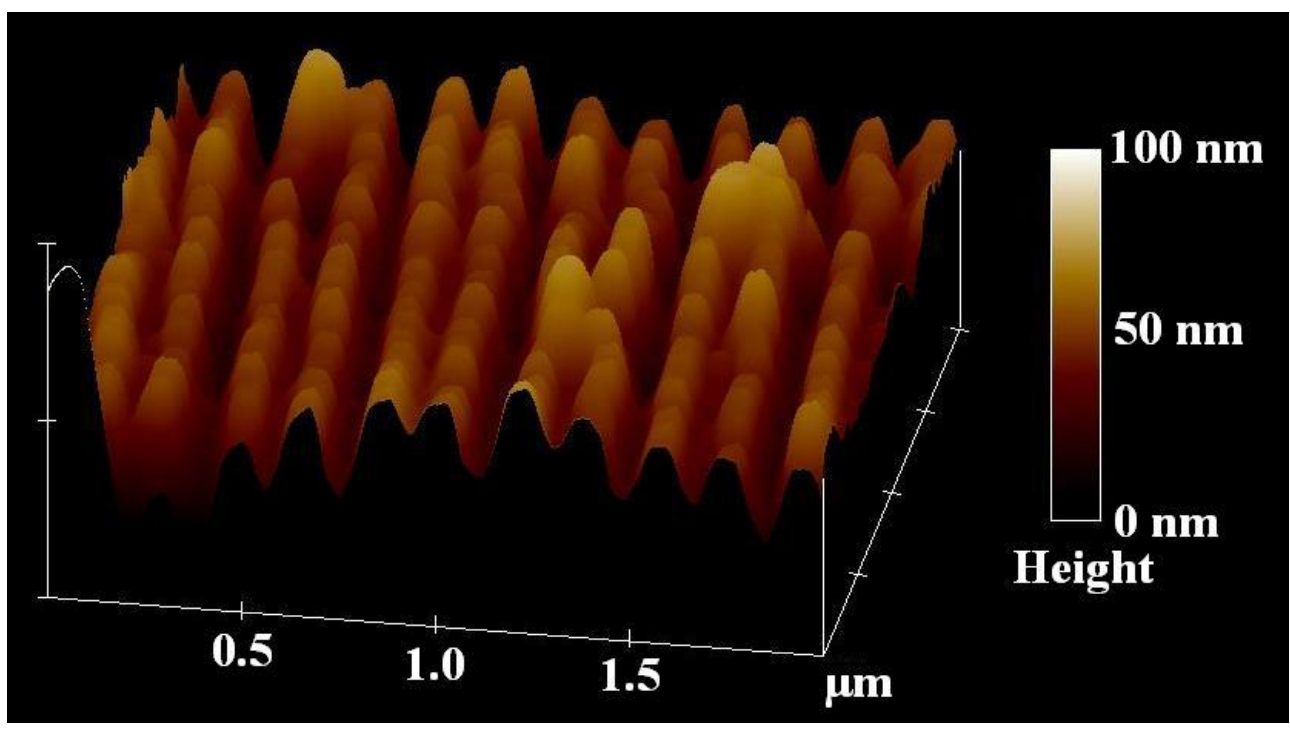

Figure 5-3(e): Tilted AFM section view of the AFM results after performing R2RNIL on PET using the electroform of the mold.

\subsection{Discussion}

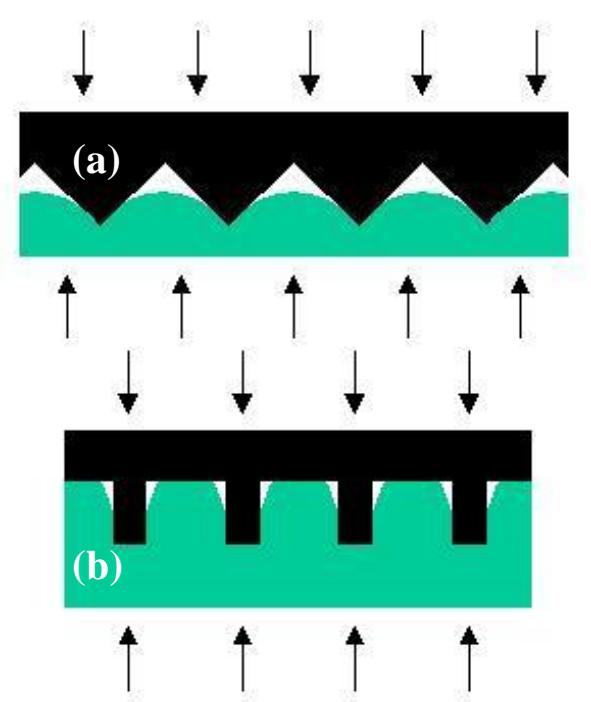

Figure 5-4: Illustration of improper mold filling due to shallow mold angle (a), and better mold filling with sharp mold angle (b).
It was predicted that features should begin to emboss once the temperature of the polymer rises higher than its glass transition temperature. In the case of the replication of the $30 \mu \mathrm{m}$ mold patterns, the incomplete filling of the mold may be due to a combination of the two following causes. The first of these proposed causes is the shallow angle of the sawtooth pattern that does not sufficiently force the polymer between the features as a pressure is applied. This effect is illustrated in Figure 5-4 showing the mold (black, top) pressing

into the substrate film (green, bottom). Since the sidewalls of the mold features in (a) are able to support a vertical stress, the film need not completely fill the mold in order to 
achieve a proper force balance; whereas in (b) with sharp mold angles, the fill must penetrate further to achieve the contact area necessary for a force balance. From the fill time analysis in Chapter 4, using the approximation of the square wave features, the features embossed at $130^{\circ} \mathrm{C}$ were not predicted to properly fill due to lack of holding time. The features embossed at $250^{\circ} \mathrm{C}$, however, still do not show complete filling, although the shape of the replicated features is showing the characteristic sawtooth shape. The reason for incomplete filling at such elevated temperatures is possibly due to the deformation of the mold during embossing due to the presence of such high stresses.

Due to the limitation of $250^{\circ} \mathrm{C}$ mold surface temperature set by the maximum working temperature of the adhesive linking the conveyor mold, temperatures in the processing temperature range of PET $\left(\sim 300^{\circ} \mathrm{C}\right)$ were unable to be tested using the current

process. Further studies into a superior linking method for forming the conveyor mold could allow higher temperatures to be used in the patterning of features using thermal embossing R2RNIL.

\subsection{Conclusion}

It can be concluded from this research that the thermal embossing R2RNIL using a conveyor mold is possible, and is capable of replicating features down to $250 \mathrm{~nm}$. The implementation of a conveyor-type mold has the distinct advantages that the continuous mold length may be longer than the circumference of the embossing roller and has superior heat transfer capabilities. A system for thermal embossing R2RNIL was developed using basic components including a cold rolling press, induction heater, and UV light and used to successfully transfer patterns in the micro-/nanometer range. 
The Rapid Thermal Response technique was applied in the heating of the mold, which involved using induction heating to heat the surface of a thin metallic mold with a small thermal inertia. In order to replicate non-metallic structures, a method for electroforming was described and used to successfully transfer features from PMMA and ETFE substrates into a magnetic, conductive nickel-cobalt alloy.

The thermal embossing R2RNIL is sensitive to the mold temperature and the specific mold features desired for replication. For replication of patterns $30 \mu \mathrm{m}$ in height and pitch, patterns were not transferred well for temperatures slightly above its glass transition, rather the patterns transferred best when the mold surface temperature reached its melt temperature, much higher than the glass transition temperature for PET. This trend was predicted using an approximated fill analysis of the polymer melt into the mold cavities. Since complete filling was still not observed for sufficient fill time at a temperature of $250^{\circ} \mathrm{C}$, improper filling must be caused by a different mechanism such as mold deformation. For patterns $250 \mathrm{~nm}$ in linewidth with a $375 \mathrm{~nm}$ period replication did not occur at temperatures less than the melt temperature of the substrate. The positive effects of increased mold temperature are likely to continue as the processing temperature of PET is approached, but due to limitations on the mold geometry this could not be tested using the current process. 


\section{CHAPTER 6}

\section{FUTURE WORK}

Due to the lack of complete filling of the molds using the current thermal embossing R2RNIL system, modification are necessary to properly address these issues. The first modification that could be instituted is the introduction of a larger embossing roller. An increased embossing roller diameter would provide the following two positive effects on pattern transfer fidelity: increased embossing contact area leading to an increased embossing time, and increased holding time allowing for proper film cooling to avoid negative relaxation effects such as relaxation.

A more advanced cooling system is also needed if thermal embossing R2RNIL is to become a viable industrial process. Convective air cooling used in this project was sufficient to provide proper temperature control for a small number of cycles until the average temperature of the system became too high for further molding. The implementation of a water-cooled system for film cooling during the holding stage and for cooling of various components from excess heat would be a feasible improvement toward the steady-state operation of the thermal embossing R2RNIL process.

A further setback encountered in the advancement of R2RNIL lies with the mold itself. For the process to be operated continuously, the mold must be looped around the embossing roller and one or more conveyor roller. A method of properly linking together smaller molds into a larger conveyor mold is necessary to bring the surface temperature of the mold to desired temperatures. The limiting factor on mold heating temperature in the preceding experimentation was the adhesive link between mold sections. If a method 
of joining mold sections using a carefully controlled soldering or welding technique, this would increase the possible working temperature of the system.

In order to further drive down the size of the replicated features using this process, a magnetic, conductive mold must be made with such small features. Most, if not all, of the sub-100nm features produced using modern techniques are done so in polymer or glass (silicon) substrates, neither of which are metallic or conductive. In this project, electroforming was used to replicate certain surface patterns, but was unsuccessful in some cases due to adhesion problems encountered during the process. For future progress in thermal embossing R2RNIL, advancements must be made in the electroforming process, or additional preparatory procedures must be introduced to allow electroforming of non-adhesive molds.

Lastly, for proper insight into the micro- and nanoscale flowing of polymer melt into mold features during embossing conditions mechanical flow simulations should be preformed and compared with the experimental results. In this project, embossing conditions were recorded, and these values will be sent to Professor Donggang Yao at the School of Polymer, Textile and Fiber Engineering Department of Georgia Institute of Technology for micro-/nanoscale flow simulations. The outcome of the flow simulations, combined with the experimental embossing results will allow a prediction of the ideal mold pattern geometries and process conditions, which will be a necessary step toward the industrial acceptation of Roll-to-Roll Nanoimprint Lithography. 


\section{APPENDIX: INDUCTION HEATER TUNING AND CODE}

The following method for tuning the induction heater in this project was used, requiring only the use of a computer workstation and an RS-485 connection to the induction heater (no LCR meter required). The induction heater used in the thermal embossing R2RNIL experiments discussed was an Ameritherm Novastar 20kW unit. Since the induction heater used in this project has a maximum output frequency of $485 \mathrm{kHz}$, it is known that the only suitable resonance frequencies for the induction coil and workpiece will be below this value. Using the Hyperterminal program in conjunction with the RS-485 serial connection to the induction heater, code was used to force the induction heater to operate between specific frequencies and find a resonant frequency. Since the highest resonant frequency is desired, it is convenient to work from $485 \mathrm{kHz}$ down to determine this value.

Checking for a resonant frequency using $100 \mathrm{kHz}$ bin sizes is sufficient, as finding two resonant frequencies in such a small range is rare. If a resonant frequency is found in a given $100 \mathrm{kHz}$ range, the induction will operate at that frequency; if no resonant frequency is found the induction heater will output an error and fault. The code for the procedure is shown below, including comments on each command (rightmost text alongside each command line). The text '001' used in the code represents the tag for a specific induction heater if multiple machines are used at once. Since only one induction heater is used in this project it is tagged as 001. If the induction heater successfully transmitted power after given these commands than the highest operating frequency for the induction coil and workpiece combination is known. If a fault were recorded after 
entering these commands, the next step would be to set the lower bound frequency to $300 \mathrm{kHz}$ and the upper bound frequency to $400 \mathrm{kHz}$ and repeat until an operating frequency is found.

pass001,test
freq001,user
start001,400
stop001,485
v001,30
t001,1
h001,on

pass001, test

freq001,user

start001,400

stop001,485

$\mathrm{t} 001,1$

h001,on

\author{
password $=$ test \\ user specifies operating frequency range \\ lower bound frequency $=400 \mathrm{kHz}$ \\ upper bound frequency $=485 \mathrm{kHz}$ \\ induction voltage $=30 \%$ maximum \\ induction heating time $=1$ second \\ heater on
}




\section{BIBLIOGRAPHY}

[1] J. Ou, G. R. Moss, and J. P. Rothstein, "Enhanced mixing in laminar flows using ultrahydrophobic surfaces," Physical Review E, vol. 76, pp. -, 2007.

[2] N. Gadegaard, E. Martines, M. O. Riehle, K. Seunarine, and C. D. W. Wilkinson, "Applications of nano-patterning to tissue engineering," Microelectronic Engineering, vol. 83, pp. 1577-1581, 2006.

[3] J. Henzie, J. E. Barton, C. L. Stender, and T. W. Odom, "Large-area nanoscale patterning: Chemistry meets fabrication," Accounts of Chemical Research, vol. 39, pp. 249-257, 2006.

[4] Y. Ekinci, H. H. Solak, C. David, and H. Sigg, "Bilayer Al wire-grids as broadband and high-performance polarizers," Optics Express, vol. 14, pp. 23232334, 2006.

[5] R. D. Chien, "Hot embossing of microfluidic platform," International Communications in Heat and Mass Transfer, vol. 33, pp. 645-653, 2006.

[6] H. Becker and C. Gartner, "Polymer microfabrication technologies for microfluidic systems," Analytical and Bioanalytical Chemistry, vol. 390, pp. 89$111,2008$.

[7] Y. N. Xia and G. M. Whitesides, "Soft lithography," Angewandte ChemieInternational Edition, vol. 37, pp. 551-575, 1998.

[8] A. Curtis and C. Wilkinson, "Nantotechniques and approaches in biotechnology," Trends in Biotechnology, vol. 19, pp. 97-101, 2001.

[9] Y. N. Xia, J. A. Rogers, K. E. Paul, and G. M. Whitesides, "Unconventional methods for fabricating and patterning nanostructures," Chemical Reviews, vol. 99, pp. 1823-1848, 1999.

[10] M. Weber, O. Benson, S. Cobb, J. Jonza, A. Ouderkirk, D. Wortman, and C. Stover, Reflective Polarizer Having Improved Properties and Optical Display with Improved Reflective Polarizer, 6543153, 2003.

[11] J. Cowan, Volume Phase Reflection Holograms and Methods for Fabricating Them, 4,888,260, 1989.

[12] R. Perkins, D. Hansen, E. Gardner, J. Thorne, and A. Robbins, Broadband Wire Grid Polarizer for the Visible Spectrum, 6122103, 2000. 
[13] S. C. Jakeway, T. Veres, and H. Luesebrink, "Transition of MEMS technology to nanofabrication," presented at Proceedings of the International Conference on MEMS, NANO and Smart Systems, 2003.

[14] J. Mohr, "LIGA - A technology for fabricating microstructures and microsystems," Sensors and Materials, vol. 10, pp. 363-373, 1998.

[15] H. Lee, S. Hong, K. Yang, and K. Choi, "Fabrication of nano-sized resist patterns on flexible plastic film using thermal curing nano-imprint lithography," Microelectronic Engineering, vol. 83, pp. 323-327, 2006.

[16] H. Lee, S. H. Hong, K. Y. Yang, and K. W. Choi, "Fabrication of $100 \mathrm{~nm}$ metal lines on flexible plastic substrate using ultraviolet curing nanoimprint lithography," Applied Physics Letters, vol. 88, pp. -, 2006.

[17] B. Cui and T. Veres, "Pattern replication of $100 \mathrm{~nm}$ to millimeter-scale features by thermal nanoimprint lithography," Microelectronic Engineering, vol. 83, pp. 902-905, 2006.

[18] L. J. Guo, "Recent progress in nanoimprint technology and its applications," Journal of Physics D-Applied Physics, vol. 37, pp. R123-R141, 2004.

[19] B. D. Gates, Q. B. Xu, M. Stewart, D. Ryan, C. G. Willson, and G. M. Whitesides, "New approaches to nanofabrication: Molding, printing, and other techniques," Chemical Reviews, vol. 105, pp. 1171-1196, 2005.

[20] S. Y. Chou, P. R. Krauss, W. Zhang, L. J. Guo, and L. Zhuang, "Sub-10 nm imprint lithography and applications," Journal of Vacuum Science \& Technology $B$, vol. 15, pp. 2897-2904, 1997.

[21] F. Chang, H. Lin, W. Lai, C. Ting, J. Tsai, S. Chang, and T. Wu, "Roll to roll processing for flexible nanophotonics," presented at Proceedings of the ASME 2007 International Design Engineering Technical Conferences \& Computers and Information in Engineering Conference, Las Vegas, Nevada, USA, 2007.

[22] T. Makela, T. Haatainen, P. Majander, and J. Ahopelto, "Continuous roll to roll nanoimprinting of inherently conducting polyaniline," Microelectronic Engineering, vol. 84, pp. 877-879, 2007.

[23] Y. Lee, C. H. Chen, C. Chiu, and C. S. Chen, "Laser-assisted and roller-based nano-imprinting technologies and their applications," presented at Proceedings of the ASME 2007 International Design Engineering Technical Conferences \& Computers and Information in Engineering Conference, Las Vegas, Nevada, USA, 2007. 
[24] S. H. Ahn, J. S. Kim, and L. J. Guo, "Bilayer metal wire-grid polarizer fabricated by roll-to-roll nanoimprint lithography on flexible plastic substrate," Journal of Vacuum Science \& Technology B, vol. 25, pp. 2388-2391, 2007.

[25] O. Nezuka, "Replication of microstructures by roll-to-roll UV-curing embossing," in Department of Mechanical and Industrial Engineering. Amherst, MA, USA: University of Massachusetts Amherst, 2007.

[26] H. Tan, A. Gilbertson, and S. Y. Chou, "Roller nanoimprint lithography," Journal of Vacuum Science \& Technology B, vol. 16, pp. 3926-3928, 1998.

[27] L. J. Guo, "High-Speed Roll-to-Roll Nanoimprinting on Flexible Plastic Substrates," presented at NSF Engineering Research and Innovation Conference, Knoxville, TN, 2008.

[28] K. Jain, Large-Area, High-Throughput, High-Resolution, Projection Imaging System, 5,285,236, 2004.

[29] K. Jain, M. Klosner, M. Zemel, and S. Raghunandan, "Flexible electronics and displays: High-resolution, roll-to-roll, projection lithography and photoablation processing technologies for high-throughput production," Proceedings of the Ieee, vol. 93, pp. 1500-1510, 2005.

[30] K. Jain, M. Zemel, and M. Klosner, "Large-area high-resolution lithography and photoablation systems for microelectronics and optoelectronics fabrication," Proceedings of the Ieee, vol. 90, pp. 1681-1688, 2002.

[31] T. H. Courtney, Mechanical Behavior of Materials, 2nd ed. Long Grove, Il, Waveland Press, Inc, 2000.

[32] J. William D Callister, Materials Science and Engineering an Introduction, 6 ed, John Wiley and Sons, Inc, 2003.

[33] G. T. Mase and G. E. Mase, Continuum Mechanics for Engineers, 2 ed, 1999.

[34] W. B. Young, "Analysis of the nanoimprint lithography with a viscous model," Microelectronic Engineering, vol. 77, pp. 405-411, 2005.

[35] "Tensile Properties vs Temperature," http://usa.dupontteijinfilms.com/informationcenter/downloads/Physical_\&_Therm al_Properties.pdf, Ed.: DuPont Teijin Films, 2003.

[36] M. T. Gale, "Replication techniques for diffractive optical elements," Microelectronic Engineering, vol. 34, pp. 321-339, 1997. 
[37] H. Schift, L. J. Heyderman, M. A. D. Maur, and J. Gobrecht, "Pattern formation in hot embossing of thin polymer films," Nanotechnology, vol. 12, pp. 173-177, 2001.

[38] D. G. Yao, "Rapid thermal response injection molding for microfeature fabrication," in Department of Mechanical and Industrial Engineering. Amherst, MA, USA: University of Massachusetts Amherst, 2001.

[39] D. G. Yao and B. Kim, "Development of rapid heating and cooling systems for injection molding applications," Polymer Engineering and Science, vol. 42, pp. 2471-2481, 2002.

[40] F. W. Curtis, High-Frequency Induction Heating. New York, McGraw-Hill, 1950.

[41] W. H. Hayt, Engineering Electromagnetics, 4th ed. New York, McGraw-Hill, 1981.

[42] C. A. Tudbury, Basics of Induction Heating, vol. 1, 1960.

[43] R. E. Haimbaugh, Practical Induction Heat Treating, ASM International, 2001.

[44] S. Park, J. Y. Wang, B. Kim, J. Xu, and T. P. Russell, "A simple route to highly oriented and ordered nanoporous block copolymer templates," Acs Nano, vol. 2, pp. 766-772, 2008.

[45] S. Park, B. Kim, J. Y. Wang, and T. P. Russell, "Fabrication of highly ordered silicon oxide dots and stripes from block copolymer thin films," Advanced Materials, vol. 20, pp. 681-+, 2008.

[46] P. Spiro, Electroforming, 2nd ed, Robert Draper LTD, 1971.

[47] B. Stein, M. Kunnavakkarn, S. Stelick, and C. Batt, "NiColoy: A versatile electroforming process for bio-sensor fabrication by embossing," Proceedings of the Ieee Sensors 2003, Vols 1 and 2, pp. 679-683, 2003.

[48] T. Watanabe, Nano-Plating: Microstructure Control Theory of Plated Film and Data Base of Plated Film Microstructure, 1st ed, Elsevier, 2004.

[49] Munson, Young, and Okiishi, Fundamentals of Fluid Mechanics, 4th ed, John Wiley \& Sons, 2002.

[50] D. C. Wilcox, Basic Fluid Mechanics, 2nd ed, DCW Industries, Inc, 2000. 